\title{
HITTING AND HOPING? \\ MEETING THE EXCHANGE RATE AND INFLATION CRITERIA DURING A PERIOD OF NOMINAL CONVERGENCE
}

\author{
JOHN LEWIS \\ CESIFO WORKING PAPER NO. 1902 \\ CATEgORY 6: MONETARY POLICY AND INTERNATIONAL FinanCE \\ JANUARY 2007
}

An electronic version of the paper may be downloaded

- from the SSRN website:

www.SSRN.com

- from the RePEc website:

Www.RePEc.org

- from the CESifo website:

www.CESifo-group.de 


\title{
HiTTING AND HOPING? MEETING THE EXCHANGE RATE AND INFLATION CRITERIA DURING A PERIOD OF NOMINAL CONVERGENCE
}

\begin{abstract}
This paper analyses the problem faced by CEECs wishing to join the Euro who must hit both an inflation and exchange rate criterion during a period of nominal convergence. This process requires either an inflation differential, an appreciating nominal exchange rate, or a combination of the two, which makes it difficult to simultaneously satisfy the exchange rate and inflation criteria. The authorities can use their monetary policy to hit one criterion, but must essentially just "hope" to satisfy the other one. The paper quantifies the likely size and speed of these convergence effects, their impact on inflation and exchange rates, and their consequences for the simultaneous compliance with both criteria under an inflation targeting setup and under a fixed exchange rate regime. The key result is that under an inflation targeting regime, the nominal appreciation implied by convergence is not big enough to threaten a breach of the exchange rate criterion, but for countries with fixed exchange rates, inflation is likely to exceed the reference value. This result is robust to plausible changes in the assumed convergence scenario.
\end{abstract}

JEL Code: E52, E61, E31.

Keywords: Central and Eastern Europe, nominal convergence, Euro adoption.

\author{
John Lewis \\ Economics and Research Division \\ De Nederlandsche Bank \\ Postbus 98 \\ 1000 AB Amsterdam \\ The Netherlands \\ j.m.lewis@dnb.nl
}

The author is grateful to Marloes Foudraine for excellent research assistance and thanks Peter Vlaar for helpful comments. The final drafting of this paper benefited from the helpful comments of Maria Demertzis. None of the above are responsible for the interpretation of the results. The views expressed are those of the author and not necessarily those of De Nederlandsche Bank 


\section{Introduction}

The eight Central and Eastern European countries (CEECs) who joined the EU on $1^{\text {st }}$ May 2004 are all obliged to join the Euro at some point in the future. Their status as member states with a derogation implies that they do not have an explicit opt-out of the single currency, but equally, member states are free to make their own decisions about the speed and strategy with which they pursue membership. Admittance to the Eurozone is based on the fulfilment of the convergence criteria laid down in Article 121 of the EC treaty- ostensibly the same "Maastricht Criteria" that governed entry for the first wave of members. In addition to nominal interest rate convergence and sound public finances, candidate countries are also required to demonstrate both exchange rate stability- defined as two years membership in ERM-II- and low inflation- defined as inflation of no more than $1.5 \%$ above the average of the lowest three EU member states ${ }^{2}$.

One key feature of the CEECs is their markedly lower price levels when compared to the Eurozone. These are tabulated below:

Table 1: Relative Price Index 2005, EU15=100

Country GDP Deflator Household Consumption

2004 Intake:

Czech Republic 54 56.4

Estonia 55.8

Latvia

48.4

55.4

Lithuania

47.4

53.3

Hungary

58.6

62.1

Poland

52.4

58.2

Slovakia

52.6

56.2

2007 Intake:

$\begin{array}{rrr}\text { Bulgaria } & 35.3 & 42.2 \\ \text { Romania } & 43.2 & 51.8\end{array}$

Lowest 3 Eurozone:

$\begin{array}{rcc}\text { Portugal } & 80.1 & 82.2 \\ \text { Greece } & 81.5 & 84.7 \\ \text { Spain } & 86.5 & 86.8 \\ & \text { Source: Eurostat } & \end{array}$

\footnotetext{
${ }^{2}$ The criterion relating to inflation is officially known in the EU Treaties as the "price stability criterion". However, it is commonly referred to as the "inflation criterion". Throughout this paper the latter term is used, so as to avoid confusion with the issue of the relative price level.
} 
Table 1 makes it clear that price levels in CEECs are substantially lower than in the Eurozone, and significantly lower than the 3 lowest Eurozone members price levels. On the basis of the GDP deflator, we can see that CEECs typically have price levels of $45-60 \%$ of the EU15, with lower figures for the 2007 intake. Since the inflation criterion is assessed on the basis of the rate of change in consumer prices (the HICP), the relative price of household consumption goods is also shown. Prices are slightly higher, but still only around 50-60\% of the EU15 level.

The ongoing convergence in the price levels between the current EMU candidates and the Eurozone- also known as nominal convergence- requires either a sustained inflation differential, a nominal exchange rate adjustment or some combination of the two. This creates a natural tension between the process of nominal convergence and the simultaneous fulfilment of the exchange rate and inflation criteria. The authorities can use monetary policy to hit one of the criteria- either to target inflation, or to fix the exchange rate- but must then sit back and simply "hope" to hit the other criterion. Whether or not this tension seriously hinders a CEECs ability to hit the convergence criteria depends on how big these convergence effects are, and for how long they persist.

In what follows we analyse three key questions. First we assess how big the tension posed by nominal convergence is; Second, we examine for how long this is likely to be a problem for CEECS; Third, we consider how the choice of exchange rate regime affects a country's ability to simultaneously fulfil the exchange rate and inflation criteria.

We take it as given that a country wishes to join the Euro, and simply look at how the process of nominal convergence affects a countries ability to meet the two criteria simultaneously. We do not analyse the welfare-based question of the desirability of Eurozone membership for any country, the costs and benefits of doing so, nor do we consider whether CEECs should aim for earlier or later entries. Rather the focus is squarely on when a country is able to meet the criteria for membership, should they wish to

To do this we utilise the model of convergence developed by Kattai (2006). This assumes a smooth convergence path in which both price levels and inflation rates in each CEEC converge steadily to the Eurozone values over time. This is then used to calculate the implied inflation differentials or nominal exchange rate appreciations required by the process of 
convergence. Given these figures, we are then able to assess how these convergence effects affect the ability of a CEEC to hit both Maastricht criteria.

The paper is organised as follows: Section 2 examines the economics of the convergence criteria. Section 3 describes the model used to generate convergence paths. Section 4 analyses the ability of CEECs to hit both criteria simultaneously using a simple model of price and inflation convergence. Section 5 estimate the probabilities of hitting the inflation criterion under a fixed exchange rate using data from 1997-2006 for Eurozone members and countries fixed tightly to the Euro. Final remarks are presented in section 6 .

\section{The Economics of the Convergence Criteria}

The lower relative price level in CEECs means that in equivalent basket of goods is cheaper to purchase in a CEEC than in the Eurozone. Price level convergence- also known as nominal convergence- is the process by which price levels in CEECs converge towards those of the EU15. One way of measuring the rate of change in the relative price is to consider the price of the consumer basket in a given CEEC, denominated in Euros and converted at the prevailing market exchange rate. Over time, the euro denominated price of the basket in the CEEC will rise. Throughout this paper, we refer to this as the euro denominated inflation rate, denoted by $\gamma$.

The core of the problem faced by CEECs can be summed up in the following equation. Defining $\Delta \mathrm{s}$ as the percentage change in the nominal exchange rate, and $\pi_{\mathrm{j}}$ as the (own currency) inflation rate in country $j$, we may write $\gamma$ as:

$$
\gamma_{j} \equiv \pi_{j}+\Delta s
$$

For countries which have a fixed exchange rate, $\Delta s=0$, all convergence takes place through an inflation differential, and hence $\gamma$ is simply equal to the annual inflation rate $\pi$. For countries whose monetary authorities target inflation (and have the same inflation target as the ECB), all convergence takes place through a nominal exchange rate appreciation- in this case $\gamma$ is equal to the nominal exchange rate appreciation, $\Delta s$ plus inflation 
The so-called "Impossible Trinity" result of stemming from the analysis of Mundell (1960) and Fleming (1962) states that it is not possible for governments to simultaneously target both inflation and the exchange rate in a world of capital mobility. Since freedom of capital is sine qua non of EU membership, this implies that monetary policy can either be geared to domestic stabilisation (with the exchange rate left to float) or can be used to maintain a fixed exchange rate arrangement but not both simultaneously. On these grounds, many commentators have criticised the application of the Maastricht criteria for new members as unwise, illogical or even absurd since it requires them to hit two targets with one instrument (Brooke 2005, Kenen \& Meade, 2003) or may require the use of fiscal policy to inflict a temporary recession that lowers inflation (Buiter and Grafe, 2002). We investigate this critique in section 4.

At this juncture the counterargument can be raised that the same criteria existed for the first wave of EMU participants, and that 12 countries managed to simultaneously satisfy the inflation and exchange rate criteria. Given that the criteria are specified in terms of ranges rather than specific single values, policymakers were able to tread a "middle way", keeping inflation low enough and the exchange rate stable enough to meet both criteria. Indeed, some countries achieved this whilst appearing to orientate monetary policy entirely towards one goal. For example, the Netherlands met both criteria whilst operating under a very tight exchange rate peg. Whilst no direct precedent exists for satisfying the criteria under inflation targeting, the experiences of Greece and Ireland showed that entry to EMU need not be incompatible with a strongly appreciating exchange rate during ERM-II ${ }^{3}$. This implies that the "impossible trinity" alone may be insufficient to generate a practical problem for policymakers.

The crucial difference between first and second waves of EMU expansion and the source of the CEECs difficulty is the process of nominal convergence. In other words, the process of price convergence between East and West requires a trend appreciation of the real exchange rate which, in the absence of any other shocks, will require a divergence in inflation rates and/or an upward nominal exchange rate realignment. For a given path of nominal convergence, the choice of exchange rate regime determines how this in which variable the convergence effect manifests itself. They may choose, as in the Baltic states, to fix the exchange rate tightly, let nominal convergence occur via an inflation differential and then

\footnotetext{
${ }^{3}$ See De Grauwe and Schnabl (2005) for a full discussion of Greek experience
} 
hope that inflation is low enough. Alternatively, they may choose, as in the larger central European states, to target inflation, hit the inflation criterion, let the convergence occur through a nominal appreciation and then hope that this doesn't compromise the exchange rate argument. What they cannot do is fix the exchange rate and at the same time have inflation at the same level as the Eurozone. In the standard "Impossible Trinity" analysis, the dilemma is about stabilisation in the face of shocks; but in the context of this paper, the dilemma is about how the authorities manage the process of nominal convergence.

A glance at the current figures suggests this is indeed a problem. Table 2, shows the how CEECs fare with respect to each of the criteria

Table 2: CEECs and the Maastricht Criteria

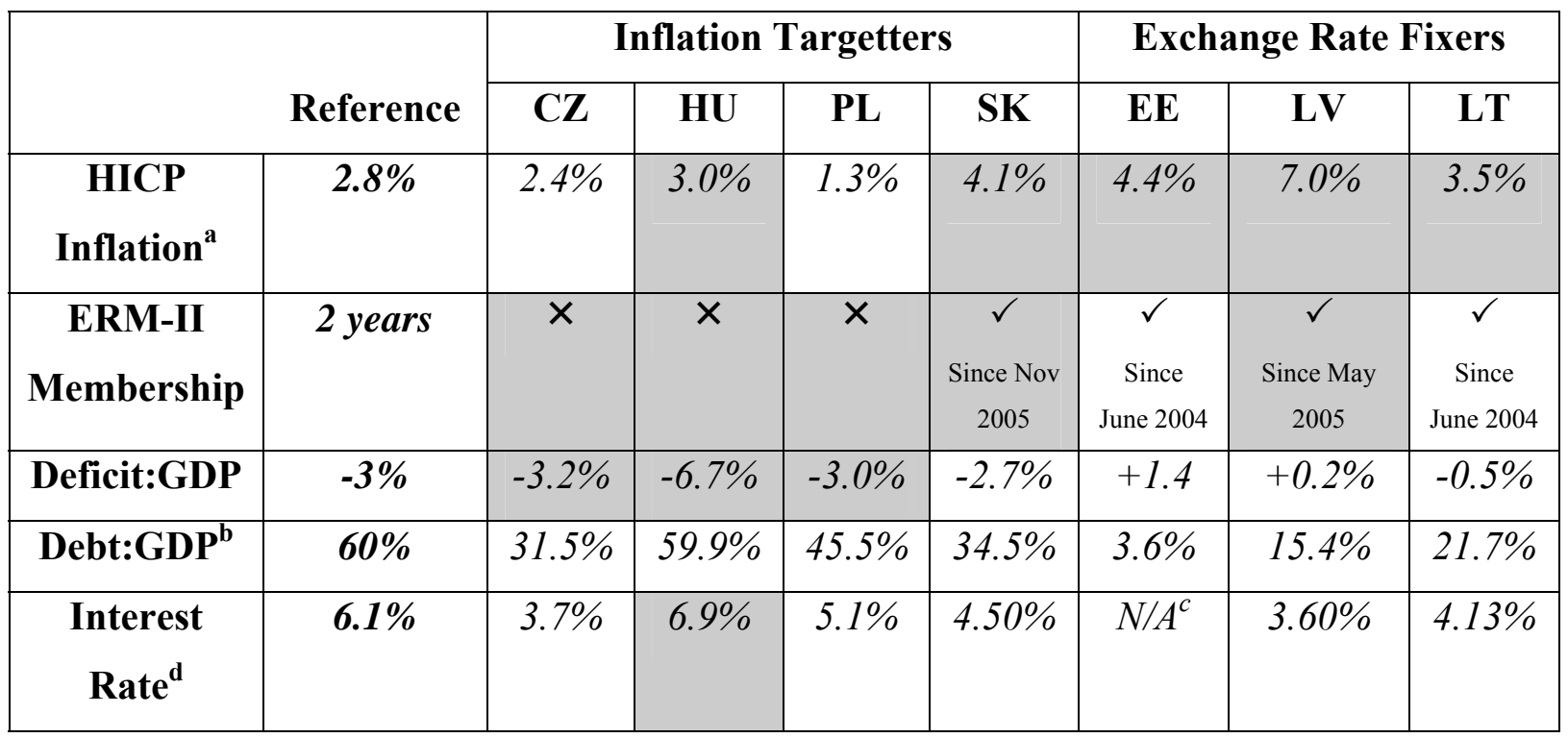

Source: Eurostat (September 2006 data), Authors own calculations

$\mathrm{CZ}=$ Czech Republic; $\mathrm{EE}=$ Estonia; HU=Hungary; $\mathrm{LV}=$ Latvia; $\mathrm{LT}=$ Lithuania, $\mathrm{PL}=$ Poland; $\mathrm{SK}=$ Slovakia; $\mathrm{BU}=$ Bulgaria; $\mathrm{RO}=$ Romania

${ }^{\mathrm{a}}$ Inflation reference group consists of Finland (1.2\%), Poland (1.3\%). and Sweden (1.4\%)

${ }^{\mathrm{b}}$ Figures for debt ratios are 2006 projections

${ }^{\mathrm{c}}$ Estonia has issued no new government debt, and hence no value is available. Previous convergence reports have suggested that on the basis of other interest rates, a negative assessment would not be forthcoming.

${ }^{\mathrm{d}}$ Interest rate reference value based on interest rates in Finland (3.6\%), Sweden (3.6\%), Poland (5.1\%)

The second column shows the reference values, and subsequent columns show each country's current figures. A white box indicates compliance, a grey box indicates non-compliance. The debt criteria is achieved by all CEECs, and the interest rate criteria by all except Hungary. 
Three countries (Czech Republic, Poland and Hungary) fail the deficit criteria, but for the Czech Republic and Poland, only a relatively small correction would be required to comply. The bulk of the problem indeed concerns the exchange rate and inflation criteria. The two countries who meet the exchange rate criteria- Estonia and Lithuania- fail on the inflation criterion. Conversely, the two countries who have successfully used inflation targeting to get inflation below the reference value- Czech Republic and Poland- have not yet joined ERM-II and hence fail the exchange rate criterion. ${ }^{4}$

Concerning the size of the "convergence effect", there is as yet, no consensus on the potential size of the annual real exchange rate appreciation associated with nominal convergence. Surveys such as Klau \& Mihaljek (2004) typically report a wide variation in figures. ${ }^{5}$ This could explain the relative downplaying of such convergence effects in the ECB and European Commission Convergence Reports which typically mention them only briefly, and conclude that there is great uncertainty over their size ${ }^{6}$. Accordingly, one key contribution of the paper is to quantify how large the convergence effects would be, for given convergence scenarios.

Despite the fact that this problem is comparatively well known in the academic sphere ${ }^{7}$, there is relatively little literature on potential solutions for policymakers in CEECs . One strand of literature on potential solutions to the problem posed by nominal convergence revolves around reformulations of the Maastricht criteria. For example, Gros (2004) advocates restricting the inflation reference group to EMU members, on the grounds that the "plus $1.5 \%$ " part of the formula gives some leeway for nominal appreciation to occur. Buiter and Grafe (2002) consider assessing inflation on the basis of tradable goods price only, Jonas (2004) proposes a redefining the reference group as the three countries with inflation closest to the ECB's target of 2\%, whilst others such as Szapáry (2000) and Buiter and Sibert (2006) suggest a derogation from the inflation criterion altogether. These proposals were took place in the context of a wider debate in the aftermath of EU enlargement concerning the

\footnotetext{
${ }^{4}$ Note that the failure to meet the exchange rate stability criterion is simply due to the fact these countries have not joined ERM-II, rather than on any consideration of the observed values of their nominal exchange rate.

${ }^{5}$ This issue is discussed in more depth in section 3.

${ }^{6}$ For example, in the December 2006 convergence report, the following wording was included for every CEEC:

"Looking further ahead, the catching-up process is also likely to have a bearing on inflation, or on the nominal exchange rate, over the coming years, given that GDP per capita and price levels are still lower in \{country\} than in the euro area... However, it is difficult to assess the exact size of the inflation effect resulting from this catching-up process."

${ }^{7}$ For a full treatment see De Broeck and Sløk (2002), Halpern and Wyplosz (2001), Eichengreen (2003)
} 
appropriateness of the existing Maastricht criteria as a means for assessing CEECs readiness to join EMU.

Whatever the merits or demerits of the current criteria, given the recent experience of Lithuania's application to join EMU, in which both the ECB and the European commission held strongly to the original Maastricht criteria, it appears highly unlikely that any reformulation or reinterpretation will occur ${ }^{8}$. Accordingly the goal of this paper is not to analyse the optimality of the criteria themselves, but rather, taking the criteria as given, to analyse the prospects for CEECs to meet them simultaneously, and in a sustainable way.

On this question, the literature is still rather sparse. De Grauwe and Schnabl (2005) consider the whether CEECs should opt for a tight peg or a gradual appreciation of their currency once inside ERM-II, but do not consider explicitly how large the convergence effects might be, or for how long they may be a problem. On the other hand, Jonas and Mishkin (2004) examine whether the Czech Republic, Poland and Hungary should persist with inflation targeting once inside ERM-II, but do not consider explicitly the effects their choice of regime may have on achieving the exchange rate criterion. By contrast, Orlowski (2005) explicitly considers the problem of meeting both criteria, and proposes that central banks aim for a gradual reduction in the inflation differential between the domestic and Eurozone inflation rates, on the grounds that this ensures compliance with the inflation criterion whilst minimising the exchange rate appreciation needed to bring this about. Accordingly, a key contribution of this paper is the analysis the conflict between fulfilling both criteria in the presence of nominal convergence, and the consideration of how the choice of entry strategy affects the chances of doing so.

\section{Modelling Nominal Convergence in CEECs}

\subsection{Modelling Methodology}

The first step in the analysis is to formulate a stylised account of nominal convergence. The goal here is not to model the underlying economic process generating the convergence, but rather to adopt a framework which allows us both to estimate the likely convergence paths,

\footnotetext{
${ }^{8}$ To date, the most significant redefinition of the criteria has been to exclude countries with negative inflation from the reference group (European Commission, 2004)
} 
and to conduct a number of simulations under different convergence scenarios. This is a crucial component of the analysis since the speed, endpoint and dynamics of the convergence process will have a strong bearing on the final results.

One common approach for modelling the size of convergence effects is in terms of the Balassa Samuelson (B-S) effect. Although this term is sometimes used almost interchangeably with nominal convergence, strictly speaking, the Balassa Samuelson effect is a theory which ties down differentials in prices and output to a differential in the productivity between tradable and non-tradable sectors. Theoretically speaking, it has a number of attractive properties- it can account for the stylised facts that countries with lower GDP per capita tend to have lower price levels and that tradable prices tend to be much more similar across countries than non-tradable prices; and it neatly connects nominal convergence, real convergence and productivity growth.

However, in this paper, the B-S approach is not used, for a number of reasons. On the empirical side, econometric work on the estimating size of the B-S effect tends to produce vastly different figures, depending on the methodology and data used (See Égert \& Halpern, 2005; Égert, 2006). In part, this can be attributed to the fact that even if the theory were a perfect account of the underlying economic mechanisms, sufficiently disaggregated data is not available to quantify the size of the effect empirically. To correctly uncover the size of B-S effect, one first needs to decompose output (and prices) into tradable and non-tradable sectors. Output based measures exist only at a sectoral level, and an arbitrary decomposition must then be made. Moreover, goods typically contain both a tradable and non-tradable element, meaning that data on individual goods prices is not sufficient. In addition, data on productivity are incomplete and sparse, and so the majority of studies rely on labour rather than total factor productivity estimates.

The other component of the rationale for eschewing the B-S framework concerns the difficulties of using it to forecast future developments. First, since the B-S framework ties nominal convergence to productivity, forecasts of future convergence require a forecast of future productivity growth. Second, there are number of theoretical issues concerning the future path of price levels, inflation and exchange rates. Simply extrapolating current estimates of the BS effect into to the future either implies that eventually CEECs will surpass the price level of the Eurozone, or, assuming that the B-S effect is suddenly "switched off" 
when convergence is reached implies a sudden downward jump in inflation. A further difficulty stems from results such as Égert et al (2003), who find no relationship between productivity and real exchange rates- if such results are taken seriously and used to estimate future price dynamics, they imply that CEECs will permanently have a significantly lower price level than the Eurozone, even as if, via productivity gains, real output converges to Eurozone levels.

As a basic minimum, it seems desirable to use a framework to model convergence which yields long-run properties which are dynamically sensible. For example, if- under fixed exchange rates- convergence effects generate a 3 percentage point differential between a NMS and the eurozone, we would not expect this to persist forever since this would imply the NMSs relative price level would not just surpass that of the Eurozone, but would carry on rising indefinitely. Something must be assumed about the end-point of the convergence process, and how long it takes to get there. This implies a relationship between price level convergence and convergence in $\gamma$.

These considerations form the basis of the approach adopted by Kattai (2006). We set this out briefly below. In short, this approach considers convergence in two variables- the relative price level, and, $\gamma$; and simply imposes the constraint that convergence in both variables comes to an end at the same point

What the price level converges to may be varied in this framework- and it what follows we consider both full convergence to the Eurozone price level, and convergence to $80 \%$ of the Eurozone price level. Simultaneous price and inflation convergence have an obvious intuitive appeal- namely that no sharp jumps in inflation or prices are required- and putting the two together implies another attractive property- that the bigger the price differential between a CEEC and the Eurozone at given point, the higher the inflation rate. This tallies well with the stylised fact that, $\gamma$ tends to be higher during the initial phases of the convergence process, and then slows as price levels get closer.

It should be stressed at this stage that this approach is not so much a means of forecasting the actual convergence path, but rather offers a simple but instructive means to simulate different convergence scenarios. In other words, it allows us to see what the price convergence path 
would look like for a specified length of the convergence process, and for a given endpoint. In short, allows us to ask "what if" questions, about the effects of different convergence scenarios.

Price level data begins in 1995 and runs up to 2005. We use this to estimate the trend price level and $\gamma$ in the year 2000. Given these values we project our convergence scenarios forward from 2000 onwards. A simple diagrammatic representation of the case where a country converges to Eurozone inflation rates and price levels is shown in figure 1.

\section{Figure 1: Stylised Convergence Paths}
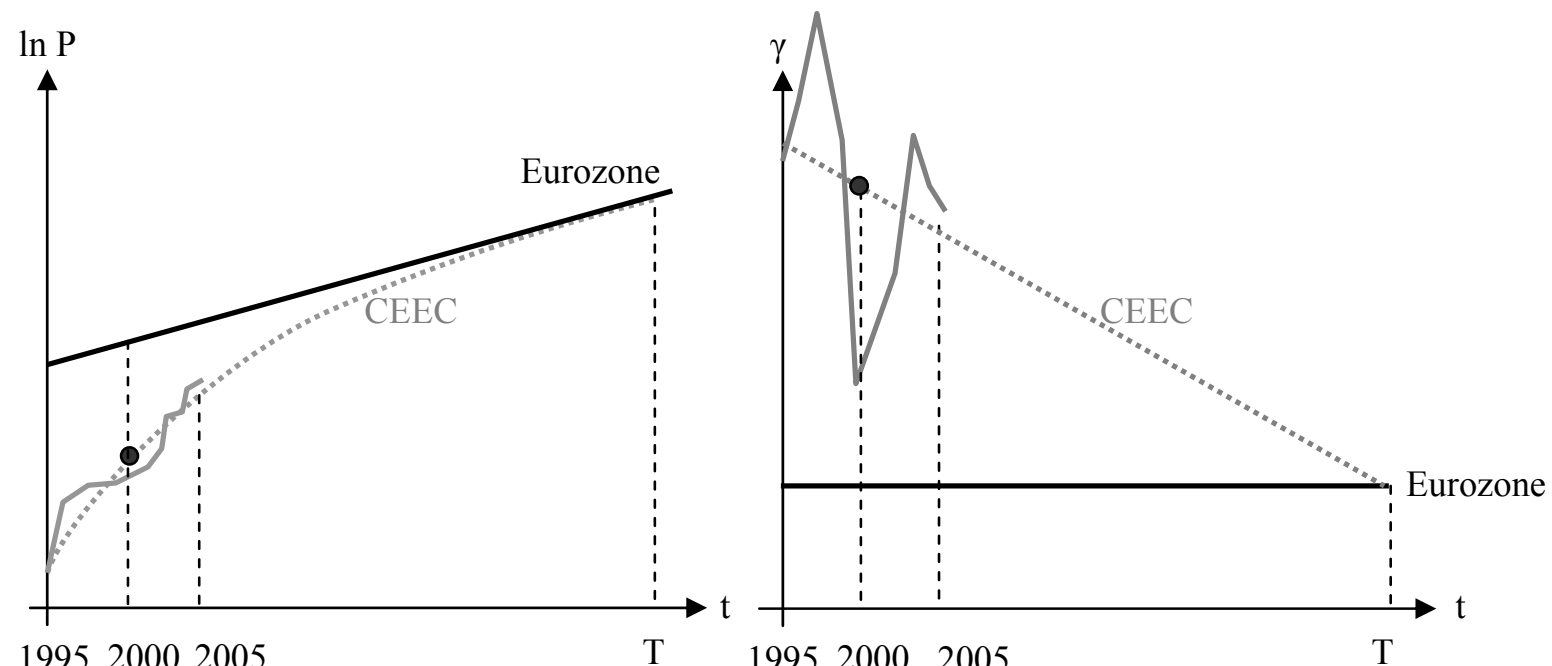

199520002005

199520002005

These diagrams also provide an intuition for the methodology used to calculate convergence speeds. We may think of the dotted lines as the underlying "trend" price levels and inflaton rates, tied down by price convergence considerations, around which the actual observed figure will fluctuate.

Formally speaking this approach implies the following equation:

$$
\frac{\bar{P}_{j}(t)}{\bar{P}_{E Z(t)}} e^{0} \int_{0}^{T}\left(\bar{\gamma}_{j}-\frac{\left(\bar{\gamma}_{j}-\bar{\pi}_{E Z}\right)}{T}\right) d t=e^{0} \int_{0 Z}^{T} \bar{\pi}_{E Z}
$$


where $\bar{P}_{j} / \bar{P}_{E Z}$ is the trend relative price level between country $j$ and the Eurozone in the year 2000 (the black dot in the left hand panel of figure 1) and where $\bar{\gamma}$ denotes the trend value of $\gamma$ in country $j$ in 2000 (the black dot in the right hand panel of figure 1). How this equation is used to generate convergence scenarios is outlined below. Figure 2 represents these relationships diagrammatically

Figure 2: Projecting Convergence
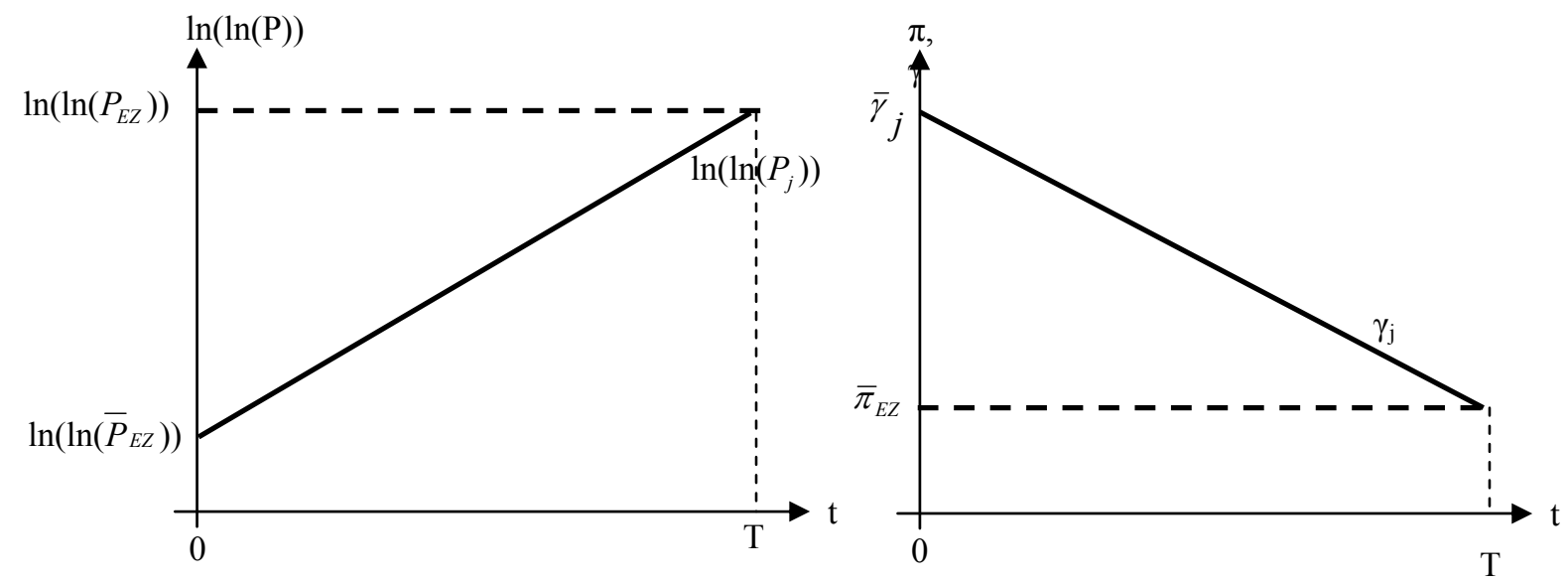

\subsection{Estimating Convergence Times}

The data for this comes from Eurostat on the relative price of the household consumption component of GDP. The HICP which used for the assessment of the inflation criterion- yields comparable rates of inflation, but cannot be used for comparing price levels across countries. Eurostat does however publish a relative price index for various components of GDP and we take the index for household final consumption as the closest approximation to the relative HICP levels.

We consider four separate convergence scenarios: 
Our first scenario is to assume that CEECs converge to $100 \%$ of the EU15 price level, and to use information on previous values of $\gamma$ plugged into (2) to estimate the convergence time. $\bar{\pi}_{E Z}$ is set at 0.02 , implying the ECB (on average) delivers inflation of $2 \%$ per annum. Averaging the double log of the observed relative price level between 19995-2005 gives us an estimate of the underlying trend relative price level in 2000. Similarly, averaging the observed values of $\gamma$ from 1995 to 2005 gives us an estimate of the underlying trend $\gamma$ in 2000 .

Given these values, and the constraint that price and inflation convergence happen simulatenously, we solve equation (1) for $\mathrm{T}$, the date at which convergence is achieved, from which we can then derive the convergence paths of the price level and $\gamma$.

However, any projections of future convergence paths are necessarily tentative, and it is therefore important to see how robust our final results will be to alternative convergence scenarios. For this reason use the framework to analyse three other cases.

Experience with current members of the Eurozone and states of the US suggests that even in a monetary union, price level differentials can remain. Therefore, we construct a second scenario whereby CEEC inflation converges to Eurozone levels, but in which CEEC price levels do not. Specifically, we assume that CEEC prices only converge to the level seen in the periphery of the Eurozone. Greece and Portugal have price levels of close to $80 \%$ of the Eurozone, so we take 0.8 as a benchmark figure. This implies that instead of (1) the following condition holds:

$$
\frac{\bar{P}_{j}}{\bar{P}_{E Z}} e^{\int_{0}^{T}\left(\bar{\gamma}_{j}-\frac{\left(\bar{\gamma}_{j}-\bar{\pi}_{E Z}\right) t}{T}\right) d t}=0.8 e^{0} \int_{0}^{T} \bar{\pi}^{0} E Z^{d t}
$$

we may then solve for $\mathrm{T}$ in the same manner as above.

Since the speed of convergence is difficult to forecast, we construct two scenarios which can be thought of as upper and lower bounds to likely convergence times. Drawing on the results 
of previous studies in convergence ${ }^{9}$, one can roughly conclude that convergence is forecast to take between 25 and 50 years. Accordingly our third scenario is a "best case" scenario where full convergence to the eurozone takes 25 years. Our fourth scenario is a "worst case" scenario in which the convergence takes 50 years. In these cases we fix T, and solve (1) for $\gamma$ given the trend price level in 2000. This gives the inflation dynamics implied by a given initial price level and convergence time.

For comparison purposes, table 3 presents the implied convergence dates rounded to the nearest year ${ }^{10}$, and the implied 2005 values of $\gamma$, using each of these approaches.

Table 3: Implied Convergence Paths

\begin{tabular}{|c|c|c|c|c|c|c|c|c|}
\hline \multirow[b]{4}{*}{ Country } & \multicolumn{8}{|c|}{ Methodology } \\
\hline & \multicolumn{4}{|c|}{ Estimate time to convergence to } & \multicolumn{4}{|c|}{ Fix time to convergence } \\
\hline & \multicolumn{2}{|c|}{$\begin{array}{c}\text { EU15 } \\
(100 \%)\end{array}$} & \multicolumn{2}{|c|}{$\begin{array}{c}\text { Periphery } \\
(80 \%)\end{array}$} & \multicolumn{2}{|c|}{ 25-year } & \multicolumn{2}{|c|}{ 50-year } \\
\hline & $\gamma_{2005}$ & Conv & $\gamma_{2005}$ & Conv & $\gamma_{2005}$ & Conv & $\gamma_{2005}$ & Conv \\
\hline $\mathbf{C Z}$ & 5.59 & 2049 & 5.59 & 2037 & 7.66 & 9.08 & 6.29 & 2050 \\
\hline $\mathbf{E E}$ & 6.40 & 2027 & 6.40 & 2017 & 6.89 & 8.11 & 5.82 & 2050 \\
\hline $\mathbf{L V}$ & 6.20 & 2043 & 6.20 & 2032 & 7.40 & 8.75 & 6.13 & 2050 \\
\hline LT & 8.12 & 2035 & 8.12 & 2027 & 7.89 & 9.36 & 6.43 & 2050 \\
\hline HU & 5.94 & 2040 & 5.94 & 2028 & 7.40 & 8.76 & 6.13 & 2050 \\
\hline $\mathbf{P L}$ & 4.69 & 2065 & 4.69 & 2048 & 7.14 & 8.42 & 5.97 & 2050 \\
\hline SK & 2.16 & 2046 & 2.16 & 2035 & 5.36 & 6.20 & 4.88 & 2050 \\
\hline BU & 5.94 & 2072 & 5.94 & 2057 & 8.07 & 9.59 & 6.54 & 2050 \\
\hline RO & 5.02 & 2063 & 5.02 & 2049 & 9.09 & 10.86 & 7.17 & 2050 \\
\hline
\end{tabular}

Source: Eurostat, Authors own calculations, (figures rounded to nearest whole year)

$\mathrm{CZ}=$ Czech Republic; EE=Estonia; HU=Hungary; LV=Latvia; $\mathrm{LT}=$ Lithuania, $\mathrm{PL}=$ Poland; SK=Slovakia; $\mathrm{BU}=$ Bulgaria; $\mathrm{RO}=$ Romania

\footnotetext{
${ }^{9}$ See the appendix for a full tabulation of estimated convergence times.

${ }^{10}$ Our analytics and calculations are conducted entirely in continuous time, but the results are rounded the nearest whole year for ease of presentation.
} 
The white columns give the 2005 value of $\gamma$ for each scenario, the grey columns give $\mathrm{T}$, the estimated year in which convergence is achieved. Concerning convergence time to $100 \%$ of EU15 price level (third column), the Baltics are the fastest to converge- taking a couple of decade, followed by the larger central European countries, with Bulgaria and Romania over 10 years behind. This conforms broadly with other estimates (see appendix for full details). If the endpoint of the convergence process is a price level of only $80 \%$ of the EU15 (fifth column), then the convergence happens approximately 10 years sooner. This reflects the fact that in the case of $80 \%$ convergence, the price level has less far to go, than if the endpoint is $100 \%$ convergence. The 25 year and 50 year cases $\left(7^{\text {th }}\right.$ and $9^{\text {th }}$ columns) show convergence dates of 2025 and 2050 by construction.

\section{Meeting the Convergence Criteria Sustainably: A Theoretical Approach}

Given these convergence scenarios outlined above, we consider how the price convergence effects associated with each of them will affect the ability of CEECs to meet the convergence criteria simultaneously and sustainably. In this section we analyse how the choice of monetary policy regime- exchange rate fixity versus inflation targeting- and the resultant manifestation of $\gamma$ in either the inflation or the exchange rate affects the ability of each CEEC to simultaneously meet both criteria.

\subsection{Stylised Representations of the Convergence Criteria}

\section{Exchange Rate Criterion}

Following Brooke (2006), Égert \& Kierzenkowski (2003) and the apparent logic of the ECB's convergence report (2006), we interpret the requirement that:

"a Member State has respected the normal fluctuation margins provided for by the Exchange Rate Mechanism of the European Monetary System without severe tensions for at least the last two years before the examination" 
in article $109 \mathrm{j}$ to mean a nominal appreciation of less than $15 \%$ from central parity ${ }^{11}$, assessed on the basis of the spot exchange rate. ${ }^{12}$

\section{$\underline{\text { Inflation Rate Criterion }^{13}}$}

In keeping with recent $\mathrm{ECB}$ convergence reports, we take the requirement of

"an average rate of inflation, observed over a period of one year before the examination, that does not exceed by more than 1 1/2 percentage points that of, at most, the three best performing Member States in terms of price stability",14

to mean $1.5 \%$ plus the average of the lowest 3 EU members (as opposed to Eurozone members), excluding all countries with negative inflation rates. Applying this formula to the EU25 from January 1998 to February 2006 and then averaging the difference between the reference value and actual Eurozone inflation yields the result that the reference value is on average $0.6 \%$ above Eurozone inflation. ${ }^{15}$ Combining this with the assumption of $2 \%$ Eurozone inflation yields the benchmark figure of $2.6 \%{ }^{16}$

The reference value (and the inflation rate of each aspiring member) is calculated using the 12 month average of the past 12 months year on year inflation rates. Since our convergence analysis implies a downward trajectory for inflation over time, a moving average over the past 12 months will, on average, yield a slightly higher number for CEECs than the current inflation. We allow for this effect by calculating the moving average HICP inflation implied by our inflation calculations.

\footnotetext{
${ }^{11}$ In what follows, we need not specify the maximum tolerated depreciation, because our calculations imply only an upward movement of the nominal exhange rate.

${ }^{12}$ In fact, the ECB's latest convergence report (ECB, 2006) this criterion was assessed on the basis of a 10-day moving average, which allowed some scope for small breaches of the $15 \%$ limit. In the context of this paper, this softening is too small to warrant attention.

${ }^{13} \mathrm{We}$ assume that our implied inflation rates calculated on the basis of the relative price of household consumption map one to one onto actual recorded HICP inflation and thus we assume the two measures will be identical. Although the two inflation rates may not be consistent month by month, as a first approximation it seems reasonable to assume there are no systematic differences in the two over time.

${ }_{14}^{14}$ Article 1 of the Protocol on the convergence criteria referred to in Article 121 of the Maastricht Treaty

${ }^{15}$ The exact figure is 0.564626 , which we round the nearest decimal place. See appendix for full details of the evolution of the reference value.

${ }^{16}$ The results in this section are robust to alternative assumptions about the reference value. Assuming the reference value is $2.8 \%$ or even $3 \%$ makes little difference. See appendix for tabulations of results using these higher reference values.
} 
The wording of the Maastricht Treaty, requires that applicants have "price performance that is sustainable", as an additional requirement alongside the satisfaction of the numerical reference value. Recent convergence reports from both the European Commission and the ECB stress the importance of sustainable compliance with the value of the inflation criterion, as opposed to simply meeting it one particular month. For example the opening section of the Commission's December 2006 convergence report, interprets compliance with the inflation criterion thus:

"The requirement of sustainability implies that a satisfactory inflation performance must essentially be achieved by the adequate behaviour of input costs and other factors influencing price developments in a structural manner, rather than reflect the influence of temporary factors. Therefore, the convergence examination includes an assessment of the underlying factors of inflation and of medium-term prospects. It is also assessed whether the country is likely to meet the reference value in the months ahead.", European Commission (2006, page 4)

\subsection{Can the convergence criteria be satisfied in a sustainable way?}

In what follows we assume that a country with a fixed exchange rate will automatically meet the exchange rate criterion, and inflation targetters will automatically meet the inflation criterion. In other words, the monetary policy framework is sufficiently credible that the monetary policymaker will indeed be able to hit whatever target they are given. Of course in reality establishing credible institutions is a vital step to achieving low inflation and stable exchange rates, but since the goal of this paper is to analyse the effect of nominal convergence, we focus our attention entirely on this. Therefore, the key question is given that the authorities can meet one of the two criteria by using their policy instrument, how a country fares with respect to the "other" criterion.

For a country with a fixed exchange rate, this means that the trend inflation rate implied by our convergence calculations must be lower than $2.6 \%$. If it is higher, then we say that a country does not meet the criterion sustainably, since any forward looking analysis will project that as inflation returns to its trend level, it will rise above the reference value. In other words, a country must meet the inflation criterion by virtue of the fact that its trend inflation is below $2.6 \%$, rather than because of a fortuitous short term departure from its trend 
value. For example, between April 2003 and August 2004, Estonian inflation was below the numerical reference value, but since price convergence calculations implied that it would eventually return to a level above the reference value, it could be argued that this convergence was not strictly speaking "sustainable",

This sustainability requirement is shown diagramatically in the left hand panel of figure 4 . For a given convergence path and time of convergence $t^{c}$ we can calculate the point, $\mathrm{t}^{\mathrm{s}}$ at which the country will successfully meet both criteria. Under a fixed exchange rate, this will occur when the moving average of inflation, $\operatorname{MA}(\pi)$ is lower than $2.6 \%$.

The right panel depicts the situation faced by an inflation targetter. The line $s_{t} / s_{t-2}$ shows the cumulative appreciation over the previous 2 years and the dotted line corresponds to the $15 \%$ upper bound. Compliance occurs when the cumulative appreciation is lower than $15 \%$. This notion of compliance assumes first that the candidate country has in fact joined ERM-II at time t-2, and with a central parity equal to the prevailing market rate- as was the case with Slovakia. In reality, a candidate may be afforded even more leeway in ERM-II, by setting the central parity at lower than the current market rate, in expectation of a future nominal appreciation (De Grauwe and Schnabl, 2005), and hence have room to appreciate of up to $30 \%$.

Moreover, our convergence path implies that until price level convergence is reached, there will be further nominal appreciations if the candidate stays in ERM-II beyond 2 years.

However, we assume that this threat to sustainability for stays of over 2 years is not taken into account by the when assessing "sustainability". 
Figure 4: Simultaneous Compliance with Both Criteria

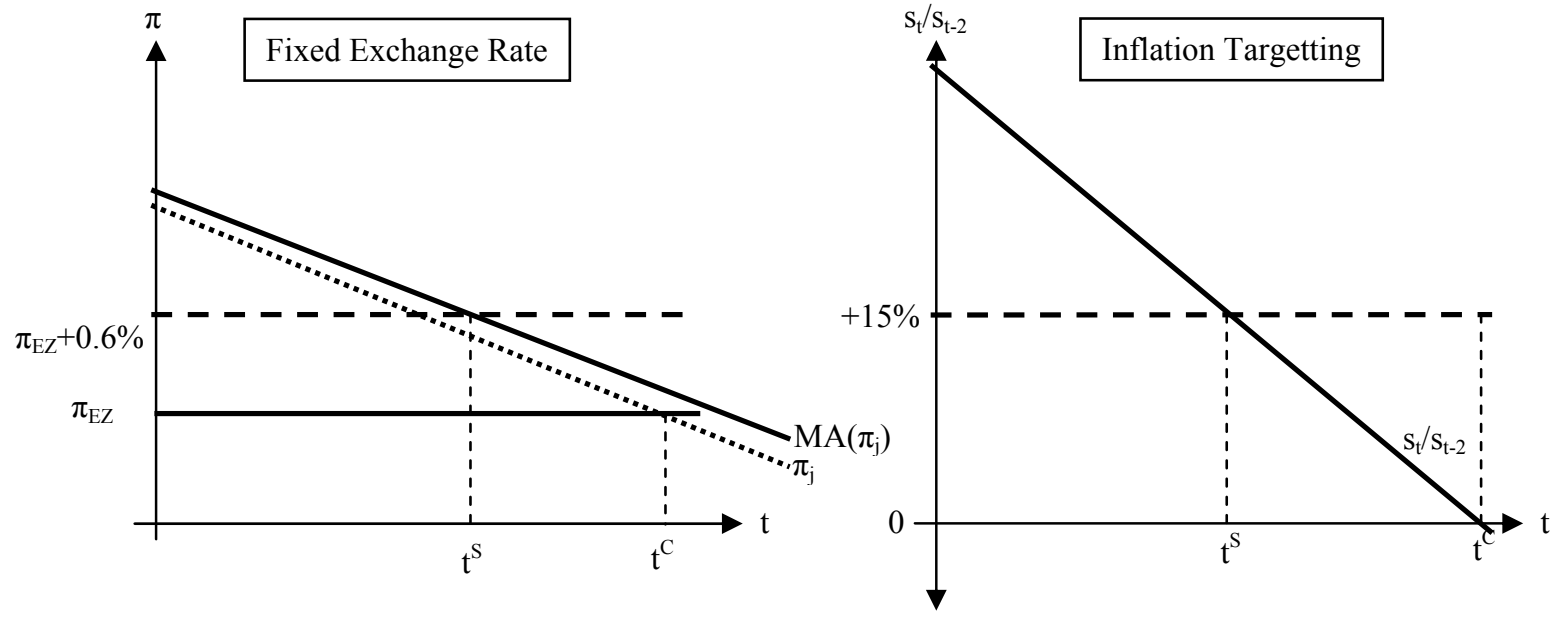

Given the convergence paths already derived, we may calculate the values of $t^{s}$ for all 8 countries, under both regimes. These are shown in table 5 .

Table 5: Compliance with the Maastricht Criteria

\begin{tabular}{|c|c|c|c|c|c|c|c|c|}
\hline & \multicolumn{8}{|c|}{ Methodology } \\
\hline & \multicolumn{4}{|c|}{ Estimate time to convergence to } & \multicolumn{4}{|c|}{ Fix time to convergence } \\
\hline & \multicolumn{2}{|c|}{$\begin{array}{c}\text { EU15 } \\
(100 \%)\end{array}$} & \multicolumn{2}{|c|}{$\begin{array}{c}\text { Periphery } \\
(80 \%)\end{array}$} & \multicolumn{2}{|c|}{ 25-year } & \multicolumn{2}{|c|}{ 50-year } \\
\hline & $\pi$ targ & Fix e & $\pi$ targ & Fix e & $\pi$ targ & Fixed e & $\pi$ targ & Fix e \\
\hline $\mathbf{C Z}$ & $\checkmark$ & 2041 & $\checkmark$ & 2030 & $\checkmark$ & 2023 & $\checkmark$ & 2044 \\
\hline EE & $\checkmark$ & 2023 & $\checkmark$ & 2015 & $\checkmark$ & 2023 & $\checkmark$ & 2043 \\
\hline HU & $\checkmark$ & 2037 & $\checkmark$ & 2027 & $\checkmark$ & 2023 & $\checkmark$ & 2043 \\
\hline $\mathbf{L V}$ & $\checkmark$ & 2031 & $\checkmark$ & 2025 & $\checkmark$ & 2023 & $\checkmark$ & 2044 \\
\hline $\mathbf{L T}$ & $\checkmark$ & 2034 & $\checkmark$ & 2024 & $\checkmark$ & 2023 & $\checkmark$ & 2043 \\
\hline $\mathbf{P L}$ & $\checkmark$ & 2050 & $\checkmark$ & 2037 & $\checkmark$ & 2023 & $\checkmark$ & 2043 \\
\hline SK & $\checkmark$ & 2039 & $\checkmark$ & 2030 & $\checkmark$ & 2023 & $\checkmark$ & 2041 \\
\hline $\mathbf{B U}$ & $\checkmark$ & 2058 & $\checkmark$ & 2046 & $\checkmark$ & 2023 & $\checkmark$ & 2044 \\
\hline RO & $\checkmark$ & 2051 & $\checkmark$ & 2040 & $\checkmark$ & 2023 & $\checkmark$ & 2045 \\
\hline
\end{tabular}

Source: Authors own calculations, (figures rounded to nearest whole year)

$\mathrm{CZ}=$ Czech Republic; EE=Estonia; HU=Hungary; LV=Latvia; LT=Lithuania, $\mathrm{PL}=$ Poland; $\mathrm{SK}=$ Slovakia;

$\mathrm{BU}=$ Bulgaria; $\mathrm{RO}=$ Romania 
Considering the fixed exchange rate case first, we see that in all countries must wait many years before they can sustainably meet the inflation criterion. Under the first scenario $(100 \%$ convergence, estimate T- third column), the first countries to meet the inflation criterion would be the Baltics in 15-20 years, with the central European nations following a decade later, and Bulgaria and Romania 10-20 years. Assuming that CEECs converge only to 80\% of the Eurozone price level ( $5^{\text {th }}$ column) brings these dates forward by about a decade. In the 25 year case, sustainable compliance occurs between 2021 and 2024, and under the 50 year case, between 2042 and 2045. The two striking things about these results are first that they are robust across all convergence scenarios, and second, that this implies the Baltic statesoften viewed as being at the front of the queue to join- would in all liklihood be unable to sustainably meet the inflation criterion for almost 2 decades. ${ }^{17}$

Turning to the case of inflation targeting, the convergence effects alone are never big enough to imply an appreciation of more than $15 \%$ over the course of a 2 year stay in ERM-II, regardless of the convergence scenario used. The actual forecast appreciations are shown below in table 6

\footnotetext{
${ }^{17}$ The Baltics would be able to sustainably meet the inflation criterion sooner if they only converged to $80 \%$ of the Eurozone price level. However, given their proximity to Scandinavian countries, it could be argued that $80 \%$ of the EU15 price level is an unrealistically low endpoint for the convergence process when Sweden and Finland have relative price levels of $110 \%$ of the EU15 level.
} 
Table 6: Forecast 2 year Appreciations within ERM-II Under Inflation Targetting (by date of joining)

\begin{tabular}{|l|ccc|ccc|cccc|ccc|}
\hline & \multicolumn{3}{|c|}{$\mathbf{1 0 0 \%}$ Conv, Est T } & \multicolumn{3}{|c|}{$\mathbf{8 0 \%}$ Conv, Est T } & \multicolumn{3}{|c|}{$\mathbf{1 0 0 \%}$ Conv, 25yr } & \multicolumn{3}{|c|}{$\mathbf{1 0 0 \%}$ Conv, 50yr } \\
\hline & 2005 & 2010 & 2015 & 2005 & 2010 & 2015 & 2005 & 2010 & 2015 & 2005 & 2010 & 2015 \\
\hline CZ & 6.84 & 5.85 & 4.87 & 6.29 & 4.90 & 3.51 & 6.31 & 5.11 & 3.92 & 5.17 & 4.57 & 3.97 \\
EE & 7.58 & 5.73 & 3.91 & 6.17 & 3.27 & 0.41 & 5.47 & 4.51 & 3.54 & 4.15 & 3.67 & 3.19 \\
HU & 7.74 & 6.28 & 4.82 & 6.85 & 4.71 & 2.59 & 6.03 & 4.91 & 3.79 & 4.83 & 4.27 & 3.71 \\
LV & 10.36 & 7.63 & 4.94 & 8.96 & 5.19 & 1.50 & 6.56 & 5.29 & 4.02 & 5.47 & 4.83 & 4.20 \\
LT & 7.18 & 5.92 & 4.67 & 6.41 & 4.58 & 2.76 & 6.03 & 4.91 & 3.79 & 4.83 & 4.27 & 3.71 \\
PL & 5.88 & 5.17 & 4.46 & 5.40 & 4.31 & 3.23 & 5.74 & 4.70 & 3.66 & 4.48 & 3.96 & 3.44 \\
SK & 7.57 & 6.48 & 5.40 & 7.04 & 5.56 & 4.08 & 6.75 & 5.43 & 4.11 & 5.71 & 5.04 & 4.38 \\
BU & 7.11 & 6.51 & 5.92 & 6.89 & 6.13 & 5.37 & 7.85 & 6.22 & 4.60 & 7.04 & 6.22 & 5.40 \\
RO & 6.66 & 5.93 & 5.20 & 6.33 & 5.35 & 4.37 & 7.01 & 5.62 & 4.23 & 6.02 & 5.32 & 4.62 \\
\hline
\end{tabular}

Source: Authors own calculations

$\mathrm{CZ}=$ Czech Republic; EE=Estonia; $\mathrm{HU}=$ Hungary; $\mathrm{LV}=$ Latvia; $\mathrm{LT}=$ Lithuania, $\mathrm{PL}=$ Poland; $\mathrm{SK}=$ Slovakia; $\mathrm{BU}=$ Bulgaria; $\mathrm{RO}=$ Romania

The number reported here is the forecast appreciation arising from convergence effects, over a hypothetical 2 year stay in ERM-II by date of joining. For all countries, and for all convergence scenario, this number is always less than $15 \%$. The later a country joins, the lower the appreciation, since $\gamma$ declines the closer to $100 \%$ the relative price level is. Equally striking is the fact that in nearly all cases, the appreciation forecast is considerably lower than 15\%. This means that CEECs who target inflation have a reasonable amount of leeway on the exchange rate criterion to cope with either short term shocks to the exchange rate. Or, alternatively, this leeway could be used to stay in ERM-II for longer than 2 years without breaching the $15 \%$ upper bound.

\subsection{How much nominal convergence do the Maastricht Criteria permit?}

The above results establish that there is an important asymmetry in the criteria- namely that an inflation targetter can do much more nominal convergence with out violating the criteria than an exchange fixer is able to. We now quantify this explicitly using equation (1), which links euro deonominated inflation rates, actual inflation rates, and the change in the nominal exchange rate: $\gamma_{j} \equiv \pi_{j}+\Delta s$ 


\section{Exchange Rate Fixer}

If $\Delta s=0$, then $\gamma_{j} \equiv \pi_{j}$. The maximum permissible inflation is $\pi_{j}=2.6 \%$ which implies that $\gamma_{j}=2.6 \%$. In words, the maximum euro denominated inflation rate that the Maastricht criteria permits an exchange fixer is $2.6 \%$.

Alternatively, we may express this in terms of the maximum permissible annual appreciation of the real exchange rate, where the latter is defined as:

$$
\triangle R E R=\Delta s+\left(\pi_{j}-\pi_{E Z}\right)
$$

Given that $\Delta s=0$, and $\pi_{E Z}=2 \%$, we may substitute in the maximum permitted inflation rate $\pi_{j}=2.6 \%$ to yield the maximum permitted real exchange rate appreciation, which comes out at $0.6 \%$.

\section{$\underline{\text { Inflation Targetter }}$}

The inflation targetter is allowed to appreciate upwards by $15 \%$ over two years, which gives an annualised nominal appreciation of $7.2 \%$. Substituting the maximum permitted appreciation, $\Delta s=7.2 \%$ and the actual inflation rate $\pi_{j}=2 \%$ into our equation: $\gamma_{j} \equiv \pi_{j}+\Delta s$, implies that $\gamma_{j}=9.2 \%$. In other words, an inflation targetter is permitted over 3 times as much euro denominated inflation as an exchange rate fixer.

In terms of the real exchange rate, substituting $\Delta s=7.2 \%$ and $\pi_{j}=\pi_{E Z}=2 \%$ into equation (4) implies a real appreciation of $7.2 \%$. Comparing this to the maximum permitted real appreciation allowed to an exchange rate fixer $(0.6 \%)$, we see that an inflation targetter is permitted over 10 times as much real exchange rate appreciation. 


\subsection{Forward Looking Concepts of Sustainability}

An additional consideration concerning sustainable compliance is how forward looking assessments of inflation and exchange rate dynamics might affect the decision on whether a country meets the criteria.

In the previous section, a fairly narrow interpretation of exchange rate stability was used- 2 years in ERM-II- which overlooks the fact that trend appreciation may mean that eventually the nominal exchange rate would breach the upper bound. A forward looking assessment of the sustainability exchange rate criterion could result in a negative assessment, on the grounds that if the stay in ERM-II were prolonged, the trend movement in the exchange rate will eventually take it above the upper bound. Whilst the argument has its appeal, it is doubtful whether the ECB and European commission would invoke (or consider) this argument. The only case of a floating exchange rate for a CEEC in ERM-II is that of Slovakia, and so far convergence reports have not invoked this argument.

Second and perhaps more seriously we ignore the problem that if an inflation targetter meets the numerical criteria, and then proceeds to join the Euro, the resultant fixing of the nominal exchange rate would then mean that real exchange rate appreciation would occur via an inflation differential. In such case, a forward looking assessment of inflation prospects would have to be made on the basis of assuming a fixed exchange rate. As we have seen, for any of the CEECs, trend inflation under a fixed exchange rate would be higher than the reference value and hence it would be difficult to sustainbly meet the inflation criterion once inside the Euro.

This opens up the paradoxical possibility that a country could sustainably meet the inflation criterion for as long as it stayed out of the Euro (and had an inflation targeting regime), but would cease to meet the inflation criterion once it had joined.

A fully forward looking assessment (on the assumption that the country joined the Euro) would conclude that the inflation criterion could not be met. But by keeping the country out of the Euro, the inflation criterion would be met. By the same token, a positive assessment of the price stability criterion which permitted entry, would then result in adoption of the Euro at which point the inflation criterion ceases to be met. 
Moreover, if the authorities decide that a judgement on sustainable compliance requires an examination of what a country's inflation would be after it has joined the euro, this has important implications for the outworkings of the Maastricht Criteria.

In such case, the inflation criterion would cease to be purely a pre-condition (based on past data) for Euro entry, it would then also be a forward looking and (in the case of a country which targets inflation) hypothetical judgement about a country's likely inflation performance after joining. This is probably in keeping with the "sustainability" requirement, but would in practice impose a forward looking component to the inflation criterion not required of the first wave of EMU members.

Given that our calculations show most countries would struggle to meet the inflation criterion under a fixed exchange rate until the price convergence process was nearly over, this could delay Eurozone entry even for inflation targetters.

\section{Meeting the Convergence Criteria Sustainably : An Empirical Approach}

For those countries who fix their exchange rate credibly, the key issue is the probability with which they can meet the inflation criterion. The analysis of the previous section concentrated on a theoretical model of trend inflation and/or nominal exchange rate appreciation based on a price convergence story. However, in reality inflation can, and does, depart substantially from the trend rates implied by nominal convergence. Accordingly, in this section we investigate empirically the role of price level differentials in determining the ability of a country to hit the inflation criterion. We do this using data from aspirant members who fix to the Euro, and from existing Eurozone members. Inflation data is published on a monthly basis, therefore we may determine at monthly frequency, whether or not a country hits the inflation criterion. This provides us with a reasonable number of observations with which to calculate the probability that a member state may hit the criterion in any one month, given their prevailing relative price level, and also on a more sustained basis. 
A direct empirical evaluation of the probability of hitting the exchange rate criterion under inflation targeting is not attempted in this section, because of the limited number of observations of aspiring members adopting inflation targets similar to that of the ECB.

To assess this we construct the variable, $C_{j, k}$, which takes records the proportion of the past $k$ months in which country $j$ has met the inflation criterion. We estimate the model for $k=$ $1,3,6,12$. This also gives us an insight into relative ease of meeting the criterion for a short period of time, versus more sustained compliance.

Since, $C_{k}$ is a discrete variable, which can take $k+1$ different values, we estimate it as an ordered probit model ${ }^{18}$. Formally speaking, we estimate the latent regression:

$$
y_{j t}=\operatorname{\beta relp}_{j t-24-k}+\varepsilon_{j t}
$$

and a series of cutoff points $Z_{1}, Z_{2} \ldots Z_{k}$ where $\operatorname{relp}_{j t}$ is the relative price level between country $i$ and the Eurozone at time $t$. This captures the idea of the previous section, that a bigger price differential implies a bigger inflation differential and hence compliance with the inflation criterion is more difficult.

The probability that $C_{k}$ takes a given value is thus:

$$
\begin{aligned}
& P \mid C=0=P\left(y<Z_{1}\right) \\
& P \mid C=\frac{x}{j}=P\left(Z_{x-1}<y<k_{s}\right), \quad \forall x<j \\
& P \mid C=1=P\left(y>Z_{k}\right)
\end{aligned}
$$

We calculate the reference value, using the average of the lowest three positive inflation rates in the the EU25. For relative prices, annual data on the relative price of household consumption was used, with linear interpolation to yield monthly figures.

\footnotetext{
${ }^{18}$ As a robustness check, an ordered logit model was also estimated. The implied probabilities of $\mathrm{C}=1$, were within $\pm 1 \%$ of those obtained under the probit specification. A full set of results is available from the author on request.
} 
The model is estimated using a sample consisting of four aspiring Eurozone membersEstonia, Latvia, Lithuania, and Slovenia plus the twelve current Eurozone members. For the latter, the sample begins from January $1^{\text {st }} 1999$, for the former we restrict the time frame to cover the time frame in which their national currency was tightly fixed to the Euro. The results are summarised in table 7 :

Table 7: Probability of Hitting the Inflation Criterion Under a Fixed Exchange Rate

\begin{tabular}{|c|c|c|c|c|}
\hline & $k=1$ & $\mathbf{k}=\mathbf{3}$ & $k=6$ & $k=12$ \\
\hline $\begin{array}{l}\hat{\beta} \\
\text { (p-value) }\end{array}$ & $\begin{array}{l}0.0120 \\
(0.000)\end{array}$ & $\begin{array}{l}0.0355 \\
(0.000)\end{array}$ & $\begin{array}{l}0.0346 \\
(0.000)\end{array}$ & $\begin{array}{l}0.0339 \\
(0.000)\end{array}$ \\
\hline $\mathbf{Z}_{\mathbf{k}}$ & 0.7670 & 3.2927 & 3.3412 & 3.5070 \\
\hline $\mathbf{N}$ & 1113 & 1103 & 1070 & 1004 \\
\hline Pseudo R-squared & 0.0258 & 0.1415 & 0.1116 & 0.0861 \\
\hline$P \mid C=1$ if Relp is & & & & \\
\hline $50 \%$ & 0.434 & 0.064 & 0.053 & 0.035 \\
\hline $60 \%$ & 0.482 & 0.122 & 0.103 & 0.070 \\
\hline $70 \%$ & 0.529 & 0.209 & 0.178 & 0.128 \\
\hline $80 \%$ & 0.577 & 0.324 & 0.282 & 0.213 \\
\hline $90 \%$ & 0.623 & 0.460 & 0.409 & 0.323 \\
\hline $100 \%$ & 0.668 & 0.600 & 0.546 & 0.452 \\
\hline
\end{tabular}

The upper half of the table gives the results of the regressions for $k=1,3,6,12$. In each equation the relative price co-efficient is highly significant, providing empirical support for the theoretical results from the previous section, that countries with lower price levels, do tend to have higher inflation, and hence find it harder to meet the inflation criterion.

By plugging $\hat{\beta}$ and each hypothesised relative price level in turn into the latent regression, and then computing the probability that $y$ exceeds the cutoff point we may obtain a probability of hitting the criterion for $k$ consecutive months given a certain relative price level. These probabilities are tabulated in the lower half of the table. 
These results confirm that, in practice, hitting the inflation criterion in the absence of an independent monetary policy is indeed easier, the more relative prices have converged. Roughly speaking, the probability of hitting the criterion in any single month $(\mathrm{k}=1)$ improves by around $0.5 \%$ for every additional percentage point that RelP increases by.

As we increase the number of consecutive months compliance required, we see that the relative price level plays a bigger role, reflecting the fact that over longer time horizons, price convergence factors play a relatively bigger role in determining price dynamics.

However, as $k$ increases we notice that two things happen. First, the more consecutive months of compliance we require, the lower the probability of success. Thus, a country with a low relative price level may be able to hit the criterion for one single month, but they find it much harder to hit it for longer periods of time. Second, the larger is $k$, the more sensitive the probability is to the price level. For example when $k=1$ (first column), a country with a relative price level of $100 \%$ of the Eurozone is about one and a half times more likely to hit the criterion for a single month, than a country with a pricel level which is $50 \%$. But if $k=12$ (last column), the probability of success for a country with a price level of $100 \%$ of the Eurozone is nearly fifteen times as great as the probability for the country with $50 \%$

Both results make sense. In the short run, inflation can diverge quite significantly from the long run trend path implied by price convergence considerations. But over longer time horizons, inflation is much more influenced by the process of price convergence. Hence, meeting the criterion for several consecutive months is harder than meeting it for a single month, and the initial relative price level has a bigger impact on success, the greater the number of consecutive months compliance is required.

To see what the results might mean in terms of probabilities for CEECs, the estimated coefficients from regression are matched up with the relative price levels implied by each of the convergence scenarios. For a given relative price level in a given year, we are then able to compute the probability of success. ${ }^{19}$ These probabilities are graphed below: 
Figure 5: Probability of $C=1, k=12 ; 100 \%$ Convergence, Estimated $T$

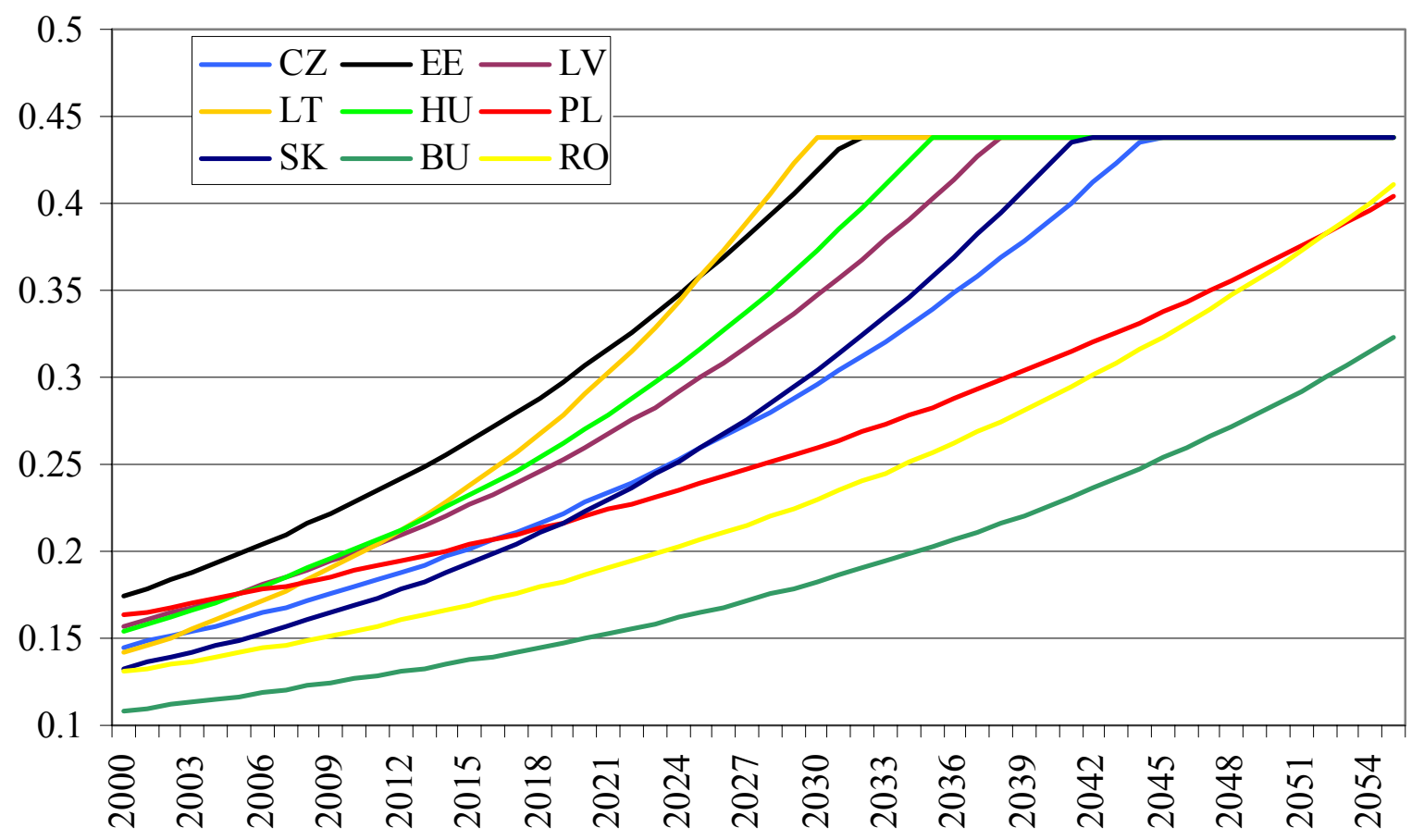

Figures 5 shows that the prospects for sustained compliance under a fixed exchange rate are relatively poor, at least for the next decade. The Baltics and Hungary have the highest probabilities (between 0.2 and 0.25 ) - on account of their having higher price levels than the other countries according to our stylised convergence scenario. However, the probabilities are significantly greater than zero, suggesting that if a CEEC is patient enough, sooner or later, a negative shock could come along which reduces inflation below the reference value for 12 consecutive months. What these regressions cannot say however, is whether this would be considered sustainable compliance with the criterion, since the longer term outlook, on the basis of convergence calculations would suggest that the inflation performance could not be sustained indefinitely. 
Figure 6: Probability of $C=1, k=12 ; 80 \%$ Convergence, Estimate $T$
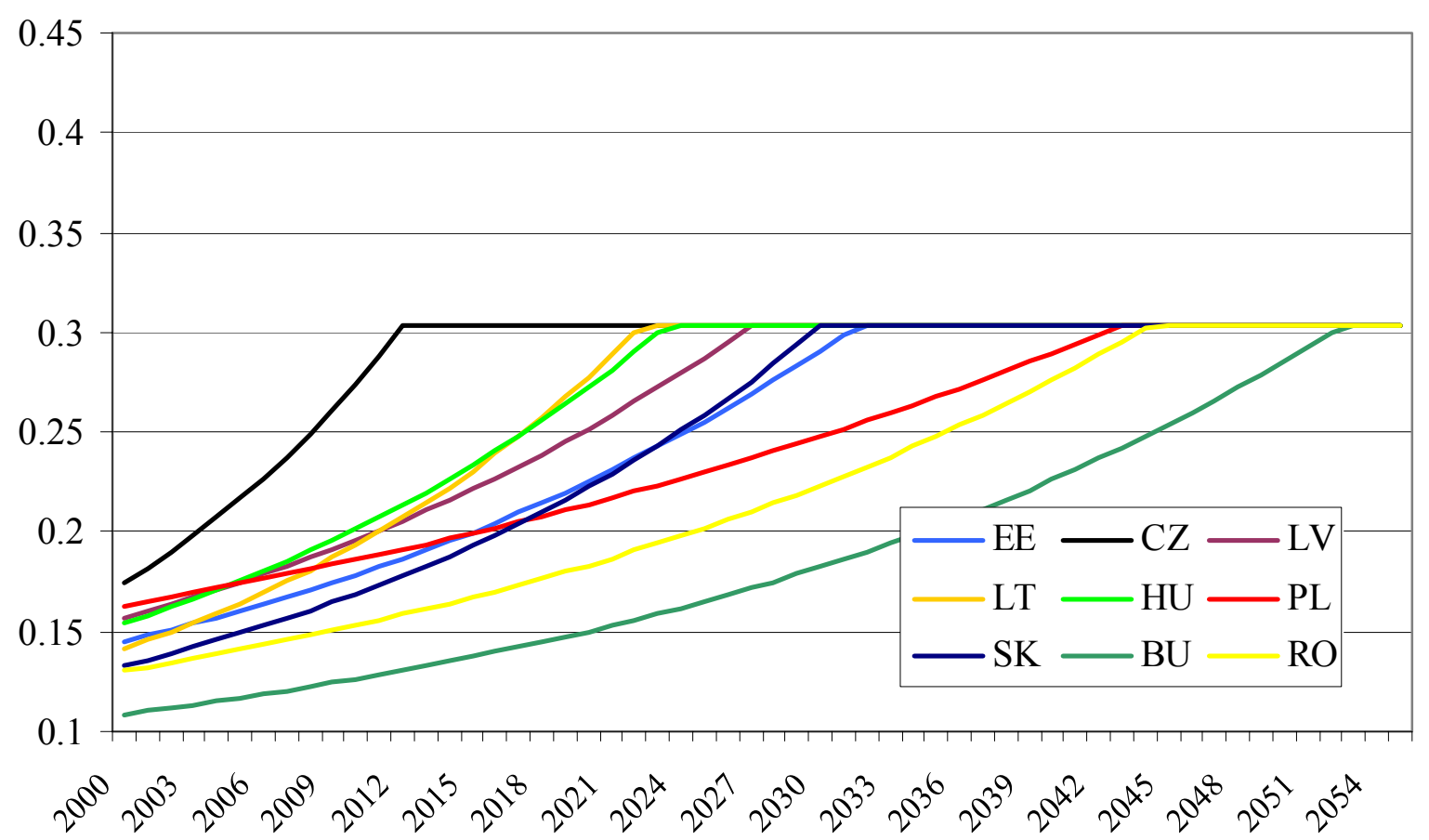

In the case of $80 \%$ convergence, the ranking of the countries (Baltics and Hungary first, rest of central Europe next, followed by Bulgaria and Romania) in order of probability is broadly the same, and the overall prospects are similarly relatively low. Note that the upper bound of the probabilities is lower than the $100 \%$ convergence case (around 0.31 as opposed to 0.44 ). This is because the price level reached at the end of the convergence process is only $80 \%$, and hence the probability of hitting the criterion associated with this is lower. However, this result should be interpreted with caution, because at the end of the convergence process, there will be no inflation differential vis a vis the Eurozone, and hence in theory, a CEEC should be just as likely to hit the criterion if it has converged to $80 \%$ of the Eurozone price level, as if it had converged to $100 \%$ of the price level. In other words, there is an incompatibility between our econometric results (which postulate that at lower price levels the probability of hitting the criterion is lower- due to convergence effects) and this particular convergence scenario which assumes that the endpoint of the convergence process is a price level of $80 \%$ of the Eurozone. 
Figure 7: Probability of $C=1, k=12 ; 100 \%$ Convergence within 25 years

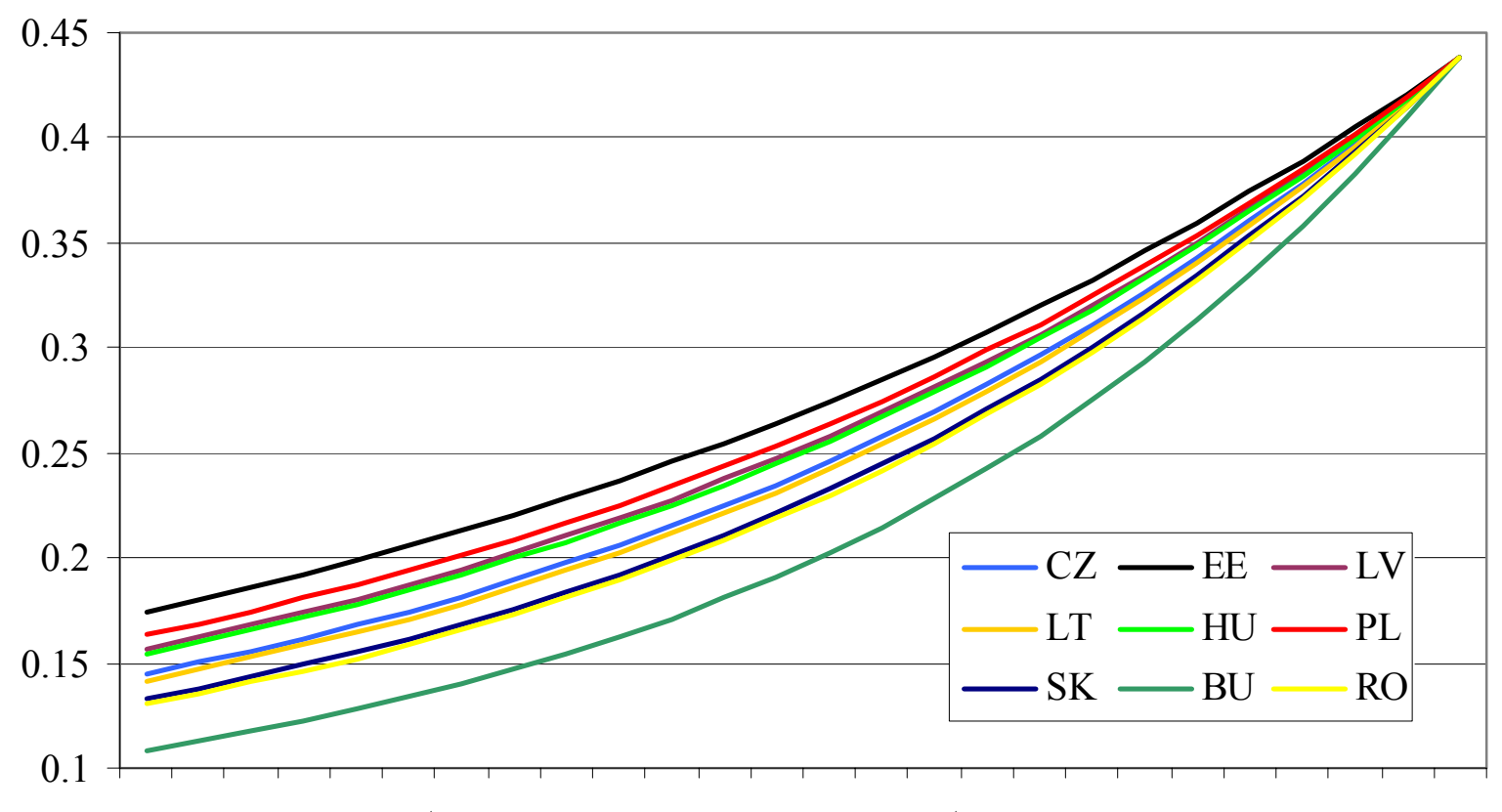

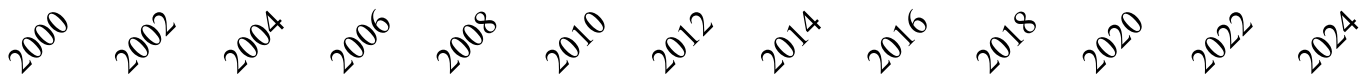

Figure 8: Probality of $C=1, k=12 ; 100 \%$ Convergence within 50 years

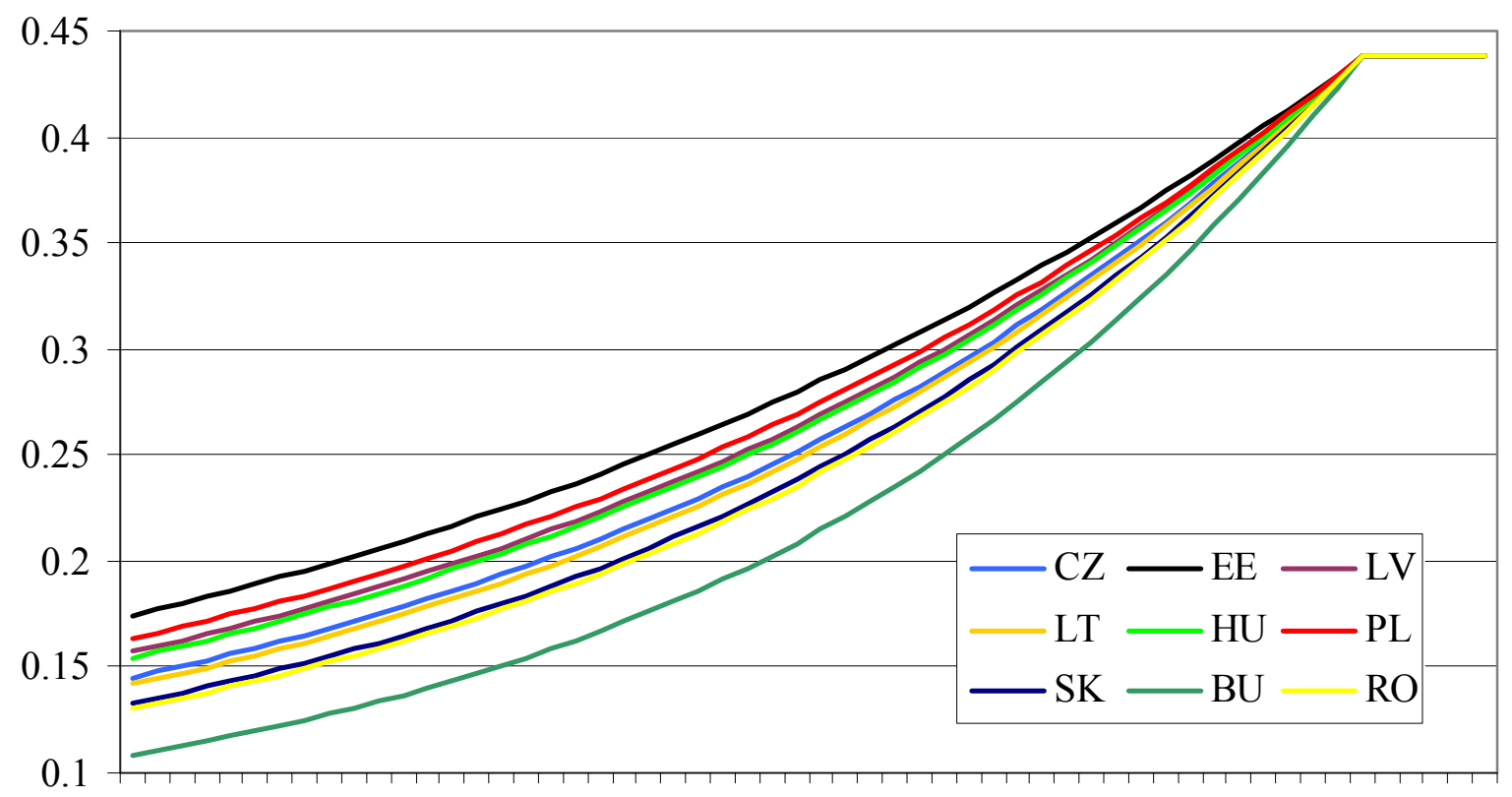

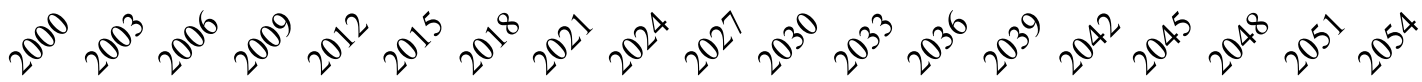

These latter figures also present a relatively pessimistic figure. First of all, in the near future, the probabilities of hitting the inflation criteria for twelve consecutive months are relatively 
low- under even the most optimistic scenario, this figure does not reach above $25 \%$ until 2020. Second, giving up monetary policy, and hence the ability to "fine tune" inflation can be rather costly- in terms of failure to meet the reference value regularly- even when the convergence process has come to an end. Even in 2050 when all countries have converged (the extreme right of the diagram), the probability of hitting the inflation criterion for 12 consecutive months is still less than 0.5 . This suggests that even after a country has completed the convergence process, and hence no structural inflation differential exists, they may still, on account of their inability to "fine tune" the inflation rate, not comply with the inflation criterion in each and every month.

\section{Concluding Remarks}

In deciding between inflation targeting and fixed exchange rates, the authorities essentially choose by which channel- nominal exchange rate appreciation or an inflation differentialconvergence in relative price levels will take place. In so doing, they also make an implicit choice about which convergence criterion they will use monetary policy to hit, and which criterion - insofar as they have no remaining monetary policy instrument- they will simply have to "hope" for.

This paper examined whether these convergence effects were strong enough to pose a problem for countries who wish to simultaneously hit the inflation and exchange rate criteria. Recent ECB convergence reports have argued that it is difficult to identify the exact size of these convergence effects on nominal exchange rates and/or inflation rates. This is undoubtedly true, since forecasts about the speed, and endpoint of the convergence process are highly uncertain, and in any one particular year, it is hard to attribute a precise share of movements in the inflation or exchange rate to convergence. However, what this paper demonstrates is that for any plausible convergence scenario these convergence effects imply, on average, persistent and sustained real exchange rate appreciations.

Having estimated the likely size of these convergence effects, the next step is to consider whether or not they pose a problem for CEECs trying to comply with the Maastricht criteria. This paper shows that the amount of real exchange rate appreciation that is permissible under 
the Maastricht criteria depends strongly on which entry strategy used. Countries with inflation targeting have much more scope to accommodate nominal convergence, and hence should find it much easier to satisfy the criteria simultaneously and sustainably. Thus, the oft repeated critique of the criteria- that they are incompatible with nominal convergence- is only true for fixed exchange rates, but not for inflation targetters. This re-enforces the conclusion of De Grauwe and Schnabl (2005), by explicitly quantifying the likely size of these convergence effects and finding that they will be large and relatively long lasting, for a wide variety of possible convergence scenarios.

Matching our results up with the observed policy regimes currently in operation in CEECs, it is the Baltic states (with fixed exchange rates) who face greater difficulties from convergence than the larger central European nations who have tended to adopt inflation targeting. The Baltic states would require a fairly significant downward shock to inflation, away from its trend value in order to meet the criterion, and may have to wait for a considerable time in ERM-II for such an event to materialise. If there is a strong emphasis on meeting the criterion for a sustained period of time, and/or a forward looking element in the assessment of the inflation criterion, the Baltic states could be out of the euro for at least a decade, and possibly two.

This also means that these states, often considered to be at the front of the queue to join, could get leapfrogged not only by Slovakia, but other inflation targetters such as the Czech Republic and Poland, for whom nominal convergence would not pose a serious obstacle to meeting the criteria.

This paper provides some support for larger central European inflation targetters to remain so in the run up to EMU, as the convergence criteria are, ceteris paribus, easier to hit with this setup, than under a tightly fixed exchange rate. However, the question of whether the Baltic countries should switch from a currency board to an inflation targeting regime is not directly considered. Whilst this does allow for more leeway to accommodate nominal convergence, inflation targeting has its own difficulties in these countries such as the very small size and high openness of the economies, and also the history of fixed exchange rates which means it is hard to forecast the impact of exchange rate movements on inflation, when there is no historical experience to go on. 
Inflation targetters could still run into difficulties, even if their exchange rate appreciates by less than $15 \%$. Whilst it is unlikely that they would be excluded on the argument that eventually the exchange rate would breach $15 \%$, they may run into trouble on the inflation criterion, if the ECB and European commission choose to examine sustainable compliance by means of a forward looking assessment of what inflation would be if the country were to join. In such case, our results concerning inflation under a fixed exchange rate suggest, all CEECs would struggle to meet the criteria- regardless of the entry strategy chosen- and hence further Eastern enlargement of the Eurozone would take decades rather than years.

One possible solution to the problem faced by exchange rate fixers is using other instruments to control inflation. For example, indirect taxes and/or administered prices could be manipulated to ensure that rate of inflation was temporarily brought down below the reference value. However, such an action would imply only generate a temporary fall in inflation and may fall foul of the sustainability requirement- especially since the fall could be traced to easily identifiable policy actions.

Alternatively, fiscal policy could be deployed to reduce aggregate demand, provoke a recession or slowdown and hence reduce inflation. That would be sufficient to meet the reference value numerically, but could well be judged insufficient to meet the sustainability part of the criterion.

It is clear from past experience that CEECs can meet the inflation criterion for extended periods of time under a fixed exchange rate- Lithuania did so for over a year in 2004/5, as did Estonia in 2003/4. The econometric analysis presented here suggests that over a forecast horizon of 12-18 months, a country's inflation may be forecast to stay below the reference value, and hence, on the basis of the forecast figures, that country be deemed to have sustainably complied with the inflation criterion. On the basis of our calculations, the probability of hitting the criterion for 12 consecutive months would, for any of the Baltic states be between 0.2 and 0.25 . Therefore, it is far from impossible that- by virtue of cyclical or other variations in the inflation rate- a country meets the reference value of inflation for a sustained period of time, and may then be judged to have complied with the inflation criterion 
Such an assessment would imply that longer term inflation developments implied by price convergence were not taken into account. In such a case, the lack of explicit consideration of the consequences of price convergence would benefit the country under consideration. However a more strict consideration of the sustainability condition would imply that countries with fixed exchange rates may have to wait until almost the end of the nominal convergence process before they are deemed to have met the criterion. 


\section{References}

Brooke, A. (2005) The Challenges of EMU Accession Faced by Catching Up-Countries: A Slovak Republic Case Study, Economics Department Working Papers No. 444, OECD, Paris

Buiter, W. (2003) Absurd Inflation Criterion for New Members, Financial Times July 14, (2004) To Purgatory and Beyond: When and How Should the Accession Countries from Central and Eastern Europe Become Full Members of EMU?, CEPR Working Paper 42, London

Buiter, W. and Grafe, C. (2002), Anchor, Float or Abandon Ship: Exchange Rate Regimes for Accession Countries, Banca Nazionale del Lavoro Quarterly Review. 55: 111-142.

Buiter, W. and Sibert, A. (2006) Europe Must Relax its Inflation Test for New Members, Financial Times, 4 May 2006

De Broeck, M. and Sløk, T. (2001). Interpreting Real Exchange Rate Movements in Transition Countries, IMF Working Paper WP/01/56.

De Grauwe, P. and Schnabl, G. (2005) Nominal versus Real Convergence-EMU Entry Scenarios for New Member States, Kyklos, Vol 58 (4) pp537-555

The Economist (2004) A May day milestone. http://www.economist.com/agenda/ displayStory.cfm?story id $=2628203$

Égert, B., Drine, I., Lommatzsch, K. and Rault, C. (2003) The Balassa Samuelson Effect in Central and Eastern Europe, Myth or Reality?, Journal of Comparative Economics, 31(3), pp $552-572$

Égert, B., and Halpern L. (2005) Equilibrium Exchange Rates in Central and Eastern Europe: A Meta-Regression Analysis, CEPR Discussion Paper 4869. 
Égert, B., and Kierzenowski (2003), Asymmetric Fluctuation Bands in ERM and ERM-II:

Lessons from the Past and Future Challenges for EU Acceding Countries, William Davidson Institute Working Paper No. 597.

Égert B., Halpern, L. and MacDonald, R. (2006), Equilibrium Exchange Rates in Transition Economies: Taking Stock of the Issues, Journal of Economic Surveys, Vol 20 (April), pp 257-324.

Eichengreen (2003), The Accession Countries Rocky Road to the Euro, Mimeo, Institute of European Studies, University of California, Berkley

European Central Bank (2006) Convergence Report, European Central Bank, Frankfurt am Main

European Commission (2001). Real convergence in candidate countries: Past performance and scenarios in the pre-accession economic programmes. http://www.

europa.eu.int/comm/economy_finance/publications/enlargement/2002/conv161101en.pdf

European Commission (2004) Convergence Report 2004: Technical Annexe, A Commission Services Working Paper.

European Commission (2006) Convergence Report December 2006, European Commission, Brussels

Fleming, J. (1962) Domestic Financial Policies under Fixed and under Floating Exchange Rates, Staff Papers, International Monetary Fund (Washington, 9 pp 369-79

Gros, D. (2004) The Maastricht Criteria after Enlargement? Old Rules for New Members, mimeo, prepared for the XVI Villa Mondragone International Economic Seminar

Hughes Hallett, A., and Lewis, J. (2006) Debt, Deficits and Accession of New Member States to the Euro, European Journal of Political Economy (forthcoming)

Halpern, L. and Wyplosz (2001).Economic Transformation and Real Exchange Rate in 
the 2000s: The Balassa-Samuelson Connection, Mimeo.

Jonas, J. (2004) Euro Adoption and Maastricht Criteria: Rules or Discretion?, ZEI Working Paper B14

Jonas, J. and Mishkin, F. (2003), Inflation Targetting in Transition Economies:

Experiences and Prospects, NBER Working Paper 9667

Kattai, R. (2005) How Could we Forget the Convergence?, mimeo, Estonian Economics Association Annual Conference

Kenen, P. and Meade, E. (2003) EU Accession and the Euro: Close Together or Far Apart, International Economics Policy Briefs, PB-09

Klau, M. and Mihaljek, D. (2004) The Balassa Samuelson Effect in Central Europe: A Disaggregated Analysis, No 46(1) pp 63-94

Mundell, R. (1960) The Monetary Dynamics of International Adjustment under Fixed and Flexible Exchange Rates, Quarterly Journal of Economics 74 (May), pp 227-57.

Orlowski; L. (2005), Targeting Relative Inflation Forecast as Monetary Policy Framework for Adopting the Euro

Szapáry (2000), Maastricht and the Choice of Exchange Rate Regime in Transition During the Run-Up to EMU, National Bank of Hungary Working Paper 2000/7.

Wagner, M., Hlouskova, J., (2005). CEEC growth projections: Certainly necessary and necessarily uncertain. Economics of Transition 13, 341-372.

World Bank (2000) Progress Toward the Unification of Europe. World Bank, Washington DC.

http://www.worldbank.org/servlet/WDSContentServer/WDSP/IB/2000/10/07/000094946 00 092605362081/Rendered/PDF/multi_page.pdf 


\section{Appendix A: Meeting the Inflation Criterion under Alternative Reference Values}

Notes:

(1) In all tables, figures are rounded to the nearest whole year

(2) $\mathrm{CZ}=$ Czech Republic; EE=Estonia; HU=Hungary; LV=Latvia; LT=Lithuania, $\mathrm{PL}=$ Poland; $\mathrm{SK}=$ Slovakia; $\mathrm{BU}=$ Bulgaria; $\mathrm{RO}=$ Romania

Case 1: 100\% Convergence, Estimate Time

\begin{tabular}{|c|c|c|c|}
\hline Country & \multicolumn{3}{|c|}{ Reference Value for Inflation } \\
\hline CZ & $\begin{array}{c}\mathbf{2 . 6 \%} \\
\text { (reported in paper) }\end{array}$ & $\mathbf{2 . 8 \%}$ & $\mathbf{3 . 0 \%}$ \\
\hline EE & 2041 & 2038 & 2036 \\
\hline LV & 2023 & 2022 & 2021 \\
\hline LT & 2037 & 2035 & 2033 \\
\hline HU & 2031 & 2030 & 2029 \\
\hline PL & 2034 & 2032 & 2030 \\
\hline SK & 2050 & 2045 & 2041 \\
\hline BU & 2039 & 2037 & 2034 \\
\hline RO & 2058 & 2053 & 2048 \\
\hline
\end{tabular}

Case 2: 80\% Convergence, Estimate Time

\begin{tabular}{|c|c|c|c|}
\hline Country & \multicolumn{3}{|c|}{ Reference Value for Inflation } \\
\hline & $\begin{array}{c}\mathbf{2 . 6 \%} \\
\text { (reported in paper) }\end{array}$ & $\mathbf{2 . 8 \%}$ & $\mathbf{3 . 0 \%}$ \\
\hline CZ & 2030 & 2028 & 2026 \\
\hline EE & 2015 & 2014 & 2013 \\
\hline LV & 2027 & 2026 & 2024 \\
\hline LT & 2025 & 2024 & 2023 \\
\hline HU & 2024 & 2023 & 2021 \\
\hline PL & 2037 & 2034 & 2030 \\
\hline SK & 2030 & 2028 & 2026 \\
\hline BU & 2046 & 2042 & 2038 \\
\hline
\end{tabular}


Case 3: Convergence Takes 25 years

\begin{tabular}{|c|c|c|c|}
\hline Country & \multicolumn{3}{|c|}{ Reference Value for Inflation } \\
\hline & $\begin{array}{c}\mathbf{2 . 6 \%} \\
\text { (reported in paper) }\end{array}$ & $\mathbf{2 . 8 \%}$ & $\mathbf{3 . 0 \%}$ \\
\hline CZ & 2023 & 2022 & 2021 \\
\hline EE & 2023 & 2022 & 2021 \\
\hline LV & 2023 & 2022 & 2021 \\
\hline LT & 2023 & 2022 & 2022 \\
\hline HU & 2023 & 2022 & 2021 \\
\hline PL & 2023 & 2022 & 2021 \\
\hline SK & 2023 & 2022 & 2022 \\
\hline BU & 2023 & 2023 & 2022 \\
\hline RO & 2023 & 2023 & 2022 \\
\hline
\end{tabular}

Case 4: Convergence Takes 50 years

\begin{tabular}{|c|c|c|c|}
\hline Country & \multicolumn{3}{|c|}{ Reference Value for Inflation } \\
\hline & $\begin{array}{c}\mathbf{2 . 6 \%} \\
\text { (reported in paper) }\end{array}$ & $\mathbf{2 . 8 \%}$ & $\mathbf{3 . 0} \%$ \\
\hline CZ & 2044 & 2042 & 2040 \\
\hline EE & 2043 & 2041 & 2038 \\
\hline LV & 2043 & 2041 & 2039 \\
\hline LT & 2044 & 2042 & 2040 \\
\hline HU & 2043 & 2041 & 2039 \\
\hline PL & 2043 & 2041 & 2039 \\
\hline SK & 2044 & 2042 & 2040 \\
\hline BU & 2045 & 2043 & 2041 \\
\hline RO & 2044 & 2043 & 2041 \\
\hline
\end{tabular}




\section{Appendix B: The Reference Value (Jan 1998-February 2006)}

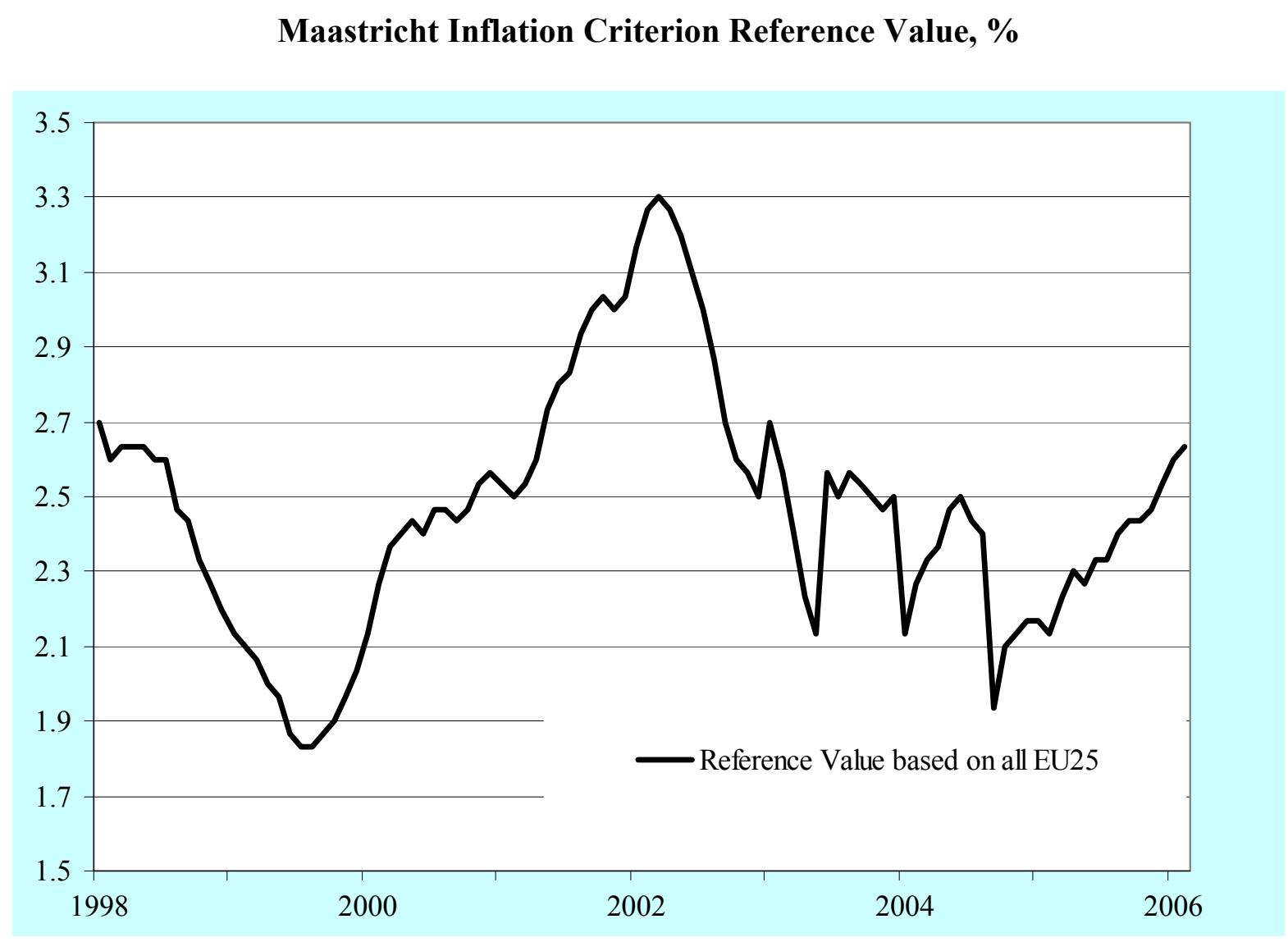

Reference value calculated as 1.5 percentage points plus the average of the lowest three (positive) inflation rates in all 25 countries. This doesn't necessarily correspond to the actual figures used in convergence reports, because prior to 2004, some "non-members" are included in this measure.

$\underline{\text { Reference Value: Summary Statistics }}$

Mean: 2.47

Median: 2.47

Standard Deviation 0.33

Maximum: 3.3

Minimum: 1.83 
Reference Value Minus Eurozone Inflation, percentage points

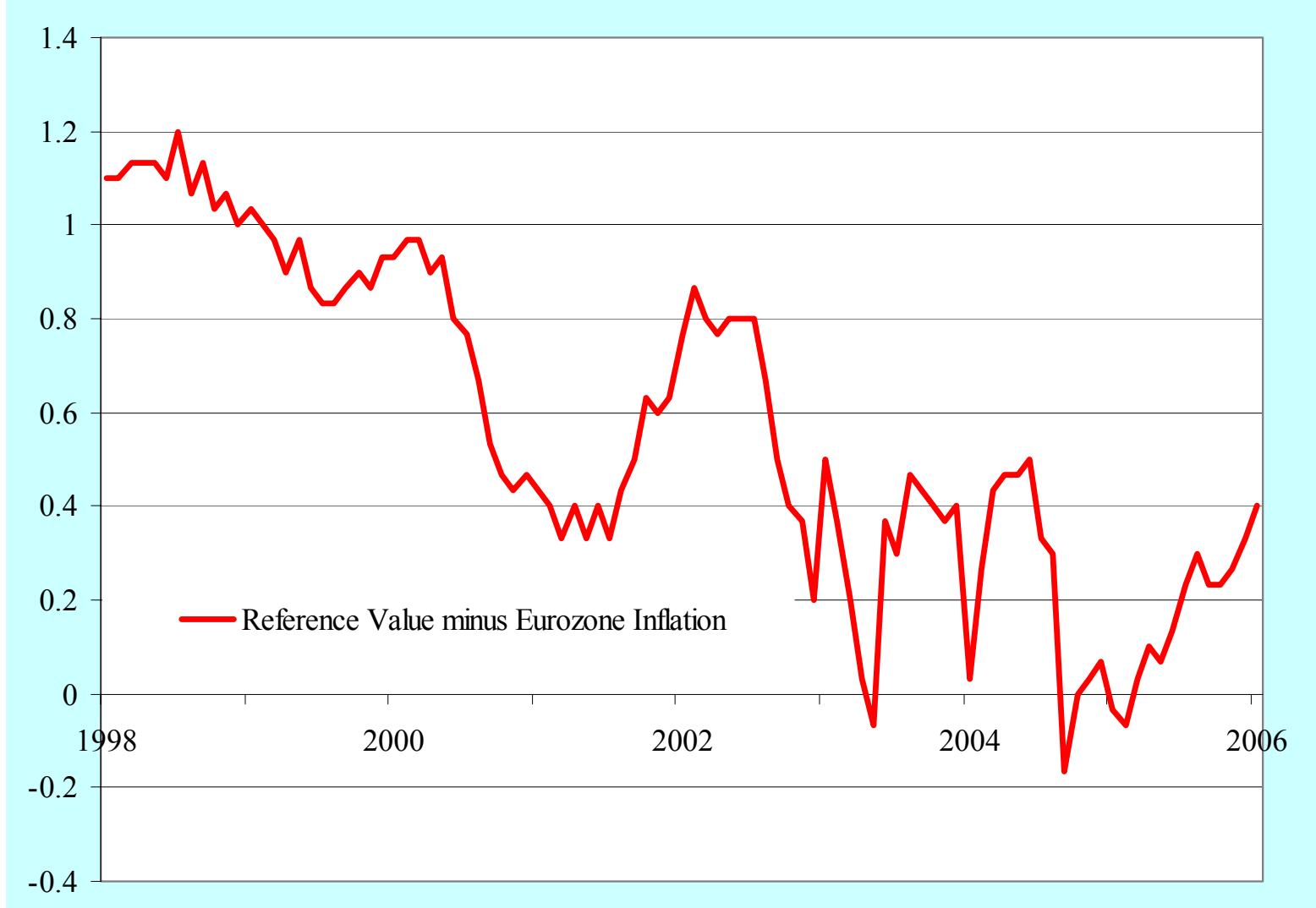

$\underline{\text { Reference value minus Eurozone Inflation: Summary Statistics }}$

Mean: 0.56

Median: 0.46

Standard Deviation: 0.35

Maximum: 1.3

Min: -0.17 


\section{Appendix C: Estimated Convergence Times from Other Studies}

Estimated Time to Convergence with EU-15, in years (from 2005)

Table taken from Hughes Hallett and Lewis (2006)

\begin{tabular}{|c|c|c|c|c|}
\hline Source: & $\begin{array}{c}\text { EIU } \\
(100 \%)\end{array}$ & $\begin{array}{c}\text { W+H } \\
(80 \%)\end{array}$ & $\begin{array}{c}\text { World } \\
\text { Bank } \\
(100 \%)\end{array}$ & $\begin{array}{c}\text { European } \\
\text { Commission } \\
(75 \%)\end{array}$ \\
\hline GDP/head & 38 & 21.2 & 13 & 11 \\
\hline Estoch Rep & 30 & 45.2 & 29 & 15 \\
\hline Hungary & 33 & 30.8 & 19 & 7 \\
\hline Latvia & 57 & 59.0 & 35 & 22 \\
\hline Lithuania & 52 & 52.2 & 35 & 27 \\
\hline Poland & 58 & 54.8 & 29 & 28 \\
\hline Slovakia & 37 & 32.9 & 26 & 16 \\
\hline Slovenia & 30 & 9.4 & 8 & -3 \\
\hline
\end{tabular}

Sources: EIU (Economist Intelligence Unit), Economist (2004) - methodology not given. Wagner and Hlouskova (2005): growth rate regression for EU-14, applied to CEEC data. World Bank (2000) - assumes 5\% real growth per annum in each CEEC country

European Commission(2001) - growth forecasts for EU-15;2004 CEEC growth forecasts. 


\section{CESifo Working Paper Series}

(for full list see www.cesifo-group.de)

1840 Erkki Koskela and Mikko Puhakka, Stability and Dynamics in an Overlapping Generations Economy under Flexible Wage Negotiation and Capital Accumulation, November 2006

1841 Thiess Buettner, Michael Overesch, Ulrich Schreiber and Georg Wamser, Taxation and Capital Structure Choice - Evidence from a Panel of German Multinationals, November 2006

1842 Guglielmo Maria Caporale and Alexandros Kontonikas, The Euro and Inflation Uncertainty in the European Monetary Union, November 2006

1843 Jan K. Brueckner and Ann G. Largey, Social Interaction and Urban Sprawl, November 2006

1844 Eytan Sheshinski, Differentiated Annuities in a Pooling Equilibrium, November 2006

1845 Marc Suhrcke and Dieter Urban, Are Cardiovascular Diseases Bad for Economic Growth?, November 2006

1846 Sam Bucovetsky and Andreas Haufler, Preferential Tax Regimes with Asymmetric Countries, November 2006

1847 Luca Anderlini, Leonardo Felli and Andrew Postlewaite, Should Courts always Enforce what Contracting Parties Write?, November 2006

1848 Katharina Sailer, Searching the eBay Marketplace, November 2006

1849 Paul De Grauwe and Pablo Rovira Kaltwasser, A Behavioral Finance Model of the Exchange Rate with Many Forecasting Rules, November 2006

1850 Doina Maria Radulescu and Michael Stimmelmayr, ACE vs. CBIT: Which is Better for Investment and Welfare?, November 2006

1851 Guglielmo Maria Caporale and Mario Cerrato, Black Market and Official Exchange Rates: Long-Run Equilibrium and Short-Run Dynamics, November 2006

1852 Luca Anderlini, Leonardo Felli and Andrew Postlewaite, Active Courts and Menu Contracts, November 2006

1853 Andreas Haufler, Alexander Klemm and Guttorm Schjelderup, Economic Integration and Redistributive Taxation: A Simple Model with Ambiguous Results, November 2006

1854 S. Brock Blomberg, Thomas DeLeire and Gregory D. Hess, The (After) Life-Cycle Theory of Religious Contributions, November 2006 
1855 Albert Solé-Ollé and Pilar Sorribas-Navarro, The Effects of Partisan Alignment on the Allocation of Intergovernmental Transfers. Differences-in-Differences Estimates for Spain, November 2006

1856 Biswa N. Bhattacharyay, Understanding the Latest Wave and Future Shape of Regional Trade and Cooperation Agreements in Asia, November 2006

1857 Matz Dahlberg, Eva Mörk, Jørn Rattsø and Hanna Ågren, Using a Discontinuous Grant to Identify the Effect of Grants on Local Taxes and Spending, November 2006

1858 Ernesto Crivelli and Klaas Staal, Size and Soft Budget Constraints, November 2006

1859 Jens Brøchner, Jesper Jensen, Patrik Svensson and Peter Birch Sørensen, The Dilemmas of Tax Coordination in the Enlarged European Union, November 2006

1860 Marcel Gérard, Reforming the Taxation of Multijurisdictional Enterprises in Europe, "Coopetition" in a Bottom-up Federation, November 2006

1861 Frank Blasch and Alfons J. Weichenrieder, When Taxation Changes the Course of the Year - Fiscal Year Adjustments and the German Tax Reform 2000/2001, November 2006

1862 Hans Jarle Kind, Tore Nilssen and Lars Sørgard, Competition for Viewers and Advertisers in a TV Oligopoly, November 2006

1863 Bart Cockx, Stéphane Robin and Christian Goebel, Income Support Policies for PartTime Workers: A Stepping-Stone to Regular Jobs? An Application to Young LongTerm Unemployed Women in Belgium, December 2006

1864 Sascha O. Becker and Marc-Andreas Muendler, The Effect of FDI on Job Separation, December 2006

1865 Christos Kotsogiannis and Robert Schwager, Fiscal Equalization and Yardstick Competition, December 2006

1866 Mikael Carlsson, Stefan Eriksson and Nils Gottfries, Testing Theories of Job Creation: Does Supply Create Its Own Demand?, December 2006

1867 Jacques H. Drèze, Charles Figuières and Jean Hindriks, Voluntary Matching Grants Can Forestall Social Dumping, December 2006

1868 Thomas Eichner and Marco Runkel, Corporate Income Taxation of Multinationals and Unemployment, December 2006

1869 Balázs Égert, Central Bank Interventions, Communication and Interest Rate Policy in Emerging European Economies, December 2006

1870 John Geweke, Joel Horowitz and M. Hashem Pesaran, Econometrics: A Bird's Eye View, December 2006 
1871 Hans Jarle Kind, Marko Koethenbuerger and Guttorm Schjelderup, Taxation in TwoSided Markets, December 2006

1872 Hans Gersbach and Bernhard Pachl, Cake Division by Majority Decision, December 2006

1873 Gunther Schnabl, The Evolution of the East Asian Currency Baskets - Still Undisclosed and Changing, December 2006

1874 Horst Raff and Michael J. Ryan, Firm-Specific Characteristics and the Timing of Foreign Direct Investment Projects, December 2006

1875 Jukka Pirttilä and Håkan Selin, How Successful is the Dual Income Tax? Evidence from the Finnish Tax Reform of 1993, December 2006

1876 Agnieszka Stążka, Sources of Real Exchange Rate Fluctuations in Central and Eastern Europe - Temporary or Permanent?, December 2006

1877 Xavier Calsamiglia, Teresa Garcia-Milà and Therese J. McGuire, Why do Differences in the Degree of Fiscal Decentralization Endure?, December 2006

1878 Natacha Gilson, How to be Well Shod to Absorb Shocks? Shock Synchronization and Joining the Euro Zone, December 2006

1879 Scott Alan Carson, Modern Health Standards for Peoples of the Past: Biological Conditions by Race in the American South, 1873 - 1919, December 2006

1880 Peter Huber, Michael Pfaffermayr and Yvonne Wolfmayr, Are there Border Effects in the EU Wage Function?, December 2006

1881 Harry Flam and Håkan Nordström, Euro Effects on the Intensive and Extensive Margins of Trade, December 2006

1882 Panu Poutvaara and Mikael Priks, Hooliganism in the Shadow of the 9/11 Terrorist Attack and the Tsunami: Do Police Reduce Group Violence?, December 2006

1883 Ruud A. de Mooij and Gaëtan Nicodème, Corporate Tax Policy, Entrepreneurship and Incorporation in the EU, December 2006

1884 Johannes Becker and Clemens Fuest, Corporate Tax Policy and International Mergers and Acquisitions - Is the Tax Exemption System Superior?, January 2007

1885 Momi Dahan and Udi Nisan, The Effect of Benefits Level on Take-up Rates: Evidence from a Natural Experiment, January 2007

1886 José García-Solanes, Francisco I. Sancho-Portero and Fernando Torrejón-Flores, Beyond the Salassa-Samuelson Effect in some New Member States of the European Union, January 2007 
1887 Peter Egger, Wolfgang Eggert and Hannes Winner, Saving Taxes Through Foreign Plant Ownership, January 2007

1888 Timothy J. Goodspeed and Andrew Haughwout, On the Optimal Design of Disaster Insurance in a Federation, January 2007

1889 Wim Groot, Henriëtte Maassen van den Brink and Bernard van Praag, The Compensating Income Variation of Social Capital, January 2007

1890 Bas Jacobs, Ruud A. de Mooij and Kees Folmer, Analyzing a Flat Income Tax in the Netherlands, January 2007

1891 Hans Jarle Kind, Guttorm Schjelderup and Frank Stähler, Newspapers and Advertising: The Effects of Ad-Valorem Taxation under Duopoly, January 2007

1892 Erkki Koskela and Rune Stenbacka, Equilibrium Unemployment with Outsourcing under Labour Market Imperfections, January 2007

1893 Maarten Bosker, Steven Brakman, Harry Garretsen, Herman de Jong and Marc Schramm, The Development of Cities in Italy 1300 - 1861, January 2007

1894 Michel Beine, Oscar Bernal, Jean-Yves Gnabo and Christelle Lecourt, Intervention Policy of the BoJ: A Unified Approach, January 2007

1895 Robert S. Chirinko and Daniel J. Wilson, State Investment Tax Incentives: A Zero-Sum Game?, January 2007

1896 Theo S. Eicher and Oliver Roehn, Sources of the German Productivity Demise Tracing the Effects of Industry-Level ICT Investment, January 2007

1897 Helge Berger, Volker Nitsch and Tonny Lybek, Central Bank Boards around the World: Why does Membership Size Differ?, January 2007

1898 Gabriel Felbermayr and Wilhelm Kohler, Does WTO Membership Make a Difference at the Extensive Margin of World Trade?, January 2007

1899 Benno Torgler and Friedrich Schneider, The Impact of Tax Morale and Institutional Quality on the Shadow Economy, January 2007

1900 Tomer Blumkin and Efraim Sadka, On the Desirability of Taxing Charitable Contributions, January 2007

1901 Frederick van der Ploeg and Reinhilde Veugelers, Higher Education Reform and the Renewed Lisbon Strategy: Role of Member States and the European Commission, January 2007

1902 John Lewis, Hitting and Hoping? Meeting the Exchange Rate and Inflation Criteria during a Period of Nominal Convergence, January 2007 